Florida International University FIU Digital Commons

3-28-2014

\title{
Spatio-temporal Analysis of Chilling Events in Mangrove Forests of South Florida
}

Bina Thapa

Florida International University, bthap001@fiu.edu

DOI: $10.25148 /$ etd.FI14040876

Follow this and additional works at: https:// digitalcommons.fiu.edu/etd

Part of the Climate Commons, and the Terrestrial and Aquatic Ecology Commons

\section{Recommended Citation}

Thapa, Bina, "Spatio-temporal Analysis of Chilling Events in Mangrove Forests of South Florida" (2014). FIU Electronic Theses and Dissertations. 1209.

https://digitalcommons.fiu.edu/etd/1209 


\section{FLORIDA INTERNATIONAL UNIVERSITY}

Miami, Florida

\section{SPATIO-TEMPORAL ANALYSIS OF CHILLING EVENTS IN MANGROVE FORESTS OF SOUTH FLORIDA}

A thesis submitted in partial fulfillment of

the requirements for the degree of

MASTER OF SCIENCE

in

ENVIRONMENT

by

Bina Thapa 
To: Dean Kenneth Furton

College of Arts and Sciences

This thesis, written by Bina Thapa, and entitled Spatio-temporal Analysis of Chilling Events in Mangrove Forests of South Florida, having been approved in respect to style and intellectual content, is referred to you for judgment.

We have read this thesis and recommend that it be approved.

$\begin{array}{r}\hline \text { Keqi Zhang } \\ \hline \text { John Withey } \\ \hline \text { Michael S. Ross, Major Professor }\end{array}$

Date of Defense: March 28, 2014

The thesis of Bina Thapa is approved.

Dean Kenneth Furton
College of Arts and Sciences

Florida International University, 2014 
(C) Copyright 2014 by Bina Thapa

All rights reserved. 


\section{DEDICATION}

To my parents 


\section{ACKNOWLEDGMENTS}

I would like to express my sincere gratitude to my major advisor Dr. Ross for his constant guidance and support throughout the study. His suggestions and helpful comments gave a good direction in my research development and writing thesis. I would also like to extend my sincere thanks to my graduate committee members, Dr. Zhang and Dr. Withey, for their constant support and patience during my thesis work. Their helpful advice helped to improve my work.

I am very grateful to the Earth and Environmental Department at FIU for supporting me to complete my graduate study in FIU. I am also thankful to Seema Sah for her help in successfully directing my lab teaching responsibilities. I am especially thankful to Danielle Crisostomo, Pablo Ruiz, and Daniel Gann for their help in all stages of research work. I would also like to thank Jay Sah, Suresh Subedi, Nathan C. Shemella and all SOFTEL lab members for their moral support.

Many thanks go to my friends, especially Praveen Subedi and Neeru Thapa for their friendship and encouragement through this period. Finally, I would like to thank my family for always encouraging me to pursue my dream. 
ABSTRACT OF THE THESIS

SPATIO-TEMPORAL ANALYSIS OF CHILLING EVENTS IN MANGROVE

FORESTS OF SOUTH FLORIDA

by

Bina Thapa

Florida International University, 2014

Miami, Florida

Michael S. Ross, Major Professor

Chilling events are infrequent but important disturbances in subtropical

Florida. When temperatures drop to near freezing, significant mortality often accrues in mangrove forests. Chilling events play a role in maintaining structural diversity in mangrove forests, and in limiting mangrove poleward distribution. I examined the spatio-temporal distribution of chilling events in mangrove forests of southern Biscayne Bay by using Landsat TM5 images since 1989. Damage was usually confined to dwarf mangrove forest, especially when chilling temperatures were moderate and short in duration. However, damage from extended and severe freezes such as in January 2010 impacted larger trees as well. Recovery is gradual, often extending over multiple years, depending on disturbance severity. Plant communities respond to repeated chilling with increase in the dominance of black mangrove. In the absence of chilling events, patch level dynamics might lead to prevalence of a more homogenous tall red mangrove canopy in these wetlands. Such a trajectory may result with increasing temperatures expected under current global climate change scenarios. 


\section{TABLE OF CONTENTS}

CONTENT

PAGE

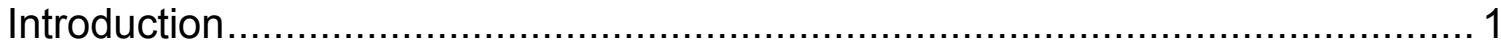

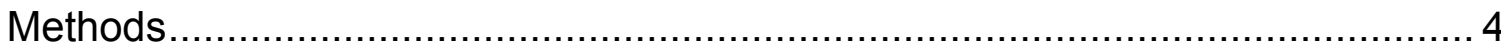

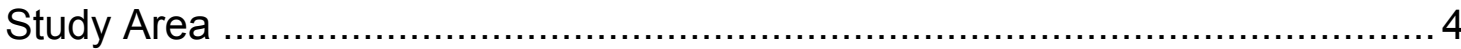

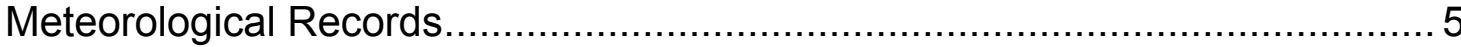

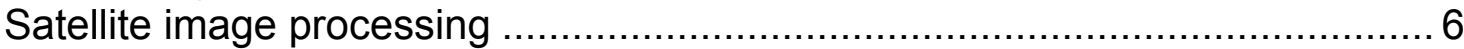

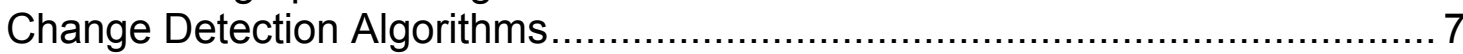

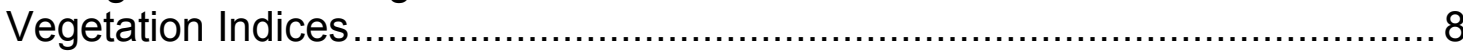

LiDAR Data Processing and Canopy Height Retrieval .............................. 12

Field Data Collection ....................................................................... 13

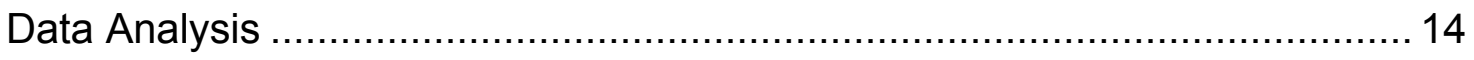

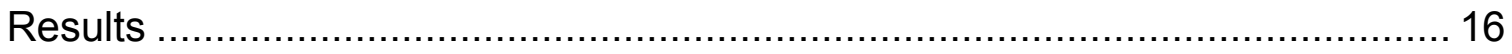

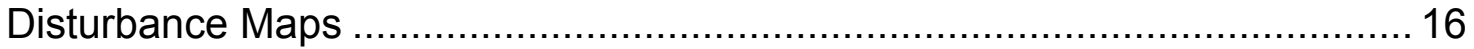

Spatial distribution of chilling events.................................................... 18

Trajectory of Vegetation Index .................................................. 19

Relationship between the chilling events and canopy height .................... 21

Community Response to Chilling Event .......................................... 23

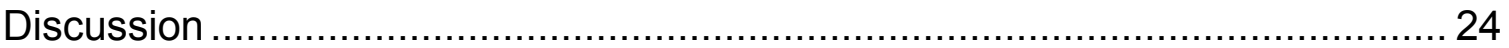

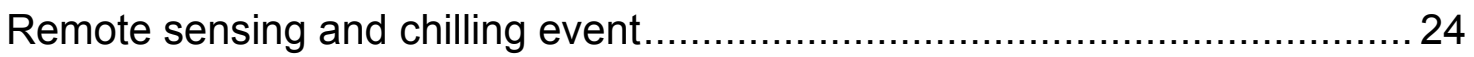

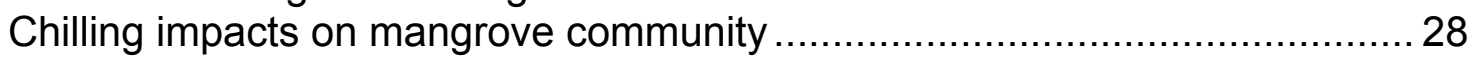

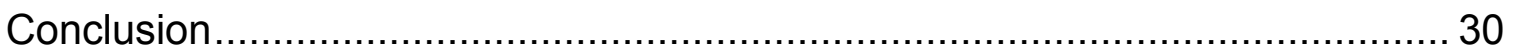

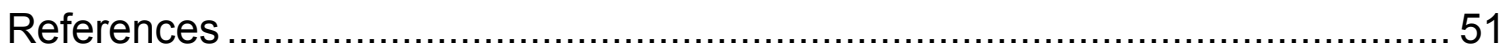




\section{LIST OF TABLES}

TABLE

PAGE

Table 1. Frequency of chilling events in Biscayne Bay, Florida and images bracketed to detect change induced by chilling event.

Table 2. Classification accuracy comparisons of image differencing method of using different vegetation indices to detect change induced by chilling events.

Table 3. Chilling events patch metrics ....................................................... 49

Table 4. MRPP analysis of chilling impacted site and unimpacted site

Table 5. Indicator species across chilling impacted sites and unimpacted sites at different years. 'Chilling' and 'No Chilling' respectively represent chilling impacted sites and unimpacted sites. 


\section{LIST OF FIGURES}

FIGURE

PAGE

Figure 1. The study area (Biscayne Bay), Florida, USA with sample plots layout in different blocks.

Figure 2. Effects of temporal resolution in detecting change induced by chilling events in blocks 3 and 4 of the study area as shown in Figure 1.

Figure 3. Spectral profiles of chilling impacted and unimpacted sites after 2010 December freeze.

Figure 4. Region of Interests (ROIs) used as ground truthing in confusion matrix.

Figure 5. Field sample plots used to test canopy height estimated from LiDAR. Field canopy height was measured in 2003.

Figure 6. Chilling induced impacted area in different chilling events.

Figure 7. Frequency distribution of chilling induced change area since 1988.... 39

Figure 8. Trajectory of mean NDMI index of the study area since 1988 to 2011. The vertical bar represents the standard deviation from the mean.

Figure 9. Vegetation recovery trend after chilling event 1989 "Christmas Freeze". The impacted area from Figure 6a was used to calculate rate of change in mean NDMI after event in impacted areas. The basal date (t) is 1988 November.

Figure 10. Vegetation recovery trend after 1996 chilling event. The impacted area from Figure $6 \mathrm{~b}$ was used to calculate rate of change in mean NDMI after event in impacted areas. The basal date (t) is 1995 November.

Figure 11. Vegetation recovery trend after 2001 chilling event. The impacted area from Figure $6 \mathrm{c}$ was used to calculate the rate of change in mean NDMI after event in impacted areas. The basal date (t) is 2000 January.

Figure 12. LiDAR canopy height (a) is classified into 5 intervals (b), with chilling events of February 2009, January 2010 and December 2010 overlaid.

Figure 13. Regression Analysis of estimated LiDAR canopy height and field canopy height. 
Figure 14. Distribution of chilling induced change areas in different canopy height classes. Relative impacted area is the area that has been impacted due to chilling event in each height class. Area of each height class was assumed 100 percent to calculate relative impacted area in percentage.

Figure 15. NMS ordination of chilling impacted sites (closed triangle and event 1) and unimpacted sites (open triangle and event 0 ) in dwarf mangrove community in study area. Impacted sites are the sites which were affected by chilling events either by 2001 or 2010.

Figure 16. Relative cover of three major species in chilling impacted and unimpacted sites. a. Red Mangrove (Rhizophora mangle) b. White Mangrove (Laguncularia racemosa) c. Black Mangrove (Avicennia germinans). Open triangles in red color represent chilling unimpacted sites and closed triangles in blue color represents chilling impacted sites (or, Event 1 indicates chilling impacted sites and event 0 indicates unimpacted sites). The symbol size represents the relative abundance of species and scale is same for all species.

Figure 17. Mean Shannon's Diversity Index $\left(\mathrm{H}^{\prime}\right)$ for chilling impacted and unimpacted sites. 'Chilling' and 'No Chilling' respectively represent chilling impacted sites and unimpacted sites. Error bars represent standard deviations. 


\section{Introduction}

Coastal mangrove forests are susceptible to frequent disturbances especially climatically-driven ones. Disturbances vary from minor changes in hydrology, temperature, or nutrients to major changes caused by hurricanes, storms, or lightnings. Chilling events, which have been documented in southern states like Florida, Texas, and Louisiana (Lugo and Zucca 1977, Olmsted et al. 1993, Ross et al. 2009), are important disturbance factors in mangrove communities. In Florida, notable chilling events were observed in 1962, 1977, 1981, 1983, 1985, 1989, 1996, and 2010 (Steven et al. 2006, Myers 1986, Rehage et al. 2010). Chilling events are often associated with the mortality of mangrove trees. Sherrod et al. (1986) documented mortality of red mangrove [Rhizophora mangle (L.)] on beaches and in estuaries of southern Texas due to severe winter freezes. In mangrove communities, massive mortality of trees after a severe chilling event creates canopy gaps. The difference in micro-environments between gap and non-gap may favor the establishment of pioneer species in the former. The spatial distribution of such disturbances, thus, creates a functional mosaic of different patches within a landscape.

Unlike other common disturbances, chilling events are specific to sub-tropical climates. When winter air temperature approaches the freezing point, it allows the formation of radiative frost. At the same time, the onset of a chilling event is marked by the settling of cold air into localized areas due to downhill drift under calm wind conditions i.e., less than 5 miles per hour (Myers 1986). Depending on the cold front, this phenomenon could recur on consecutive nights (Myers 1986, 
Olmsted et al. 1993). Tropical species like mangroves, which grow vigorously when the mean temperature is greater than $20^{\circ} \mathrm{C}$, are vulnerable to exposure to chilling temperatures (Chapman 1976). Because mangrove species are not as cold resistant as temperate-origin species, extreme temperature fluctuations between freezing mornings and warm days during a chilling event (Ross et al. 2009) may disrupt the plant's physiological function. This may lead to leaf desiccation, stem damage, and eventually, death of mangroves.

Although local chilling effects have been recorded in mangrove forests across a relatively broad temperature range (e.g., $+5^{\circ} \mathrm{C}$ to $-2^{\circ} \mathrm{C}$ (Krauss et al. 2008 , Stuart et al. 2006)), the variation in chilling impacts across mangrove species seems to affect their rangewide spatial distributions. Black mangrove [Avicennia germinans (L.)], for example, is reported to survive at temperatures down to $-4^{\circ} \mathrm{C}$ (Krauss et al. 2008) and only shows very adverse effects at temperatures below $-6.7^{\circ} \mathrm{C}$ (Steven et al. 2006). This capacity to tolerate freezing temperature extends $A$. germinans' distribution further north along the coasts of the southeastern U.S. than red or white mangrove [Laguncularia racemosa (L.) C.F. Gaertn.].

Chilling events have an important ecological role in sub-tropical climates. The intensity, duration and frequency of occurrence of chilling temperatures influence the spatial distribution of mangroves. They limit the poleward distribution of mangrove forests (Osland et al. 2012), in the process preventing their encroachment into saltmarsh in the transition zone between temperate and subtropical climates (Stevens et al. 2006, Cavanaugh et al. 2013). Structural variation in mangrove forests is also regulated by chilling events, especially when 
other factors such as low phosphorous availability do not limit mangrove tree growth. In addition, mangrove tree height is negatively influenced by frequent chilling events (Myers 1986), which ultimately accentuates dwarf structure in mangrove forests (Ross et al. 2009). Although extreme climatic events are predicted to increase in the current global warming scenario (IPCC 2007), it is likely that the frequency of freeze events will continue to decrease in the near future (Ross et al. 2009). Since structural variation and biodiversity of mangrove forests are closely linked (Duke et al. 1998), it is important to gain a better understanding of the spatio-temporal distribution of chilling events and their influence on mangrove forests.

With advancement in remote sensing technologies, the monitoring of disturbance effects in the ecosystem has become more convenient in recent years (Kennedy et al. 2007, Masek et al. 2008). For instance, the availability of medium resolution, long term Landsat data typically provides a means of understanding the long-term patterns of disturbance and their intensity (Coppin et al. 2004). Because the change in mangrove forests induced by a chilling event will cause a decrease in reflectance that is easily discriminated through Landsat images, this study uses a long-term historical Landsat dataset (1988 to 2011) in order to:

1. Produce a map of frequency and spatial distribution patterns of change induced by chilling events along a south Florida coastline from 1988 to 2011, and track post-chilling recovery.

2. Examine the relationship between the spatial distribution of chilling events and mangrove canopy height. 
3. Describe community and species responses to chilling events.

\section{Methods}

\section{Study Area}

Mangrove forests on the mainland portion of Biscayne National Park, located at the southern tip of the Florida peninsula, were selected for this study (Figure 1). Located at approximately $25^{\circ} 29^{\prime} 0.04^{\prime \prime} \mathrm{N}$ latitude and $80^{\circ} 20^{\prime} 36.96$ " W longitude, the study area comprises a continuous strip of mangrove forest of approximately $14 \mathrm{~km}$ length. It is bounded on the south by the Mowry Canal (C-103), on the east by Biscayne Bay, on the west by the L-31E canal, and extends north to the Park boundary. The area is divided into compartments by drainage ditches, which run from east to west. Soil varies from relatively deep peats close to Biscayne Bay to calcareous muds in the interior. Ross et al. (2001) documented the impacts of Hurricane Andrew (1992) as well as the local effects of two chilling events in 1996 and 2001 (Ross et al. 2009). The predominant vegetation of the study area consists of red mangrove, black mangrove, white mangrove and buttonwood [Conocarpus erectus (L.)]. Mangrove composition and structure vary consistently from coast to interior. Tall red mangrove is dominant close to the coast, though areas dominated by black and white mangroves can also be found. All three species decrease in height inland, though once average tree height reaches $\sim 1 \mathrm{~m}$ dwarf red mangroves again become dominant in most portions of the study area (Ross et al. 2001). Buttonwoods occur along the canals and drainage ditches, and are found mixed with other mangrove species in small, isolated tree islands in the dwarf forest. 


\section{Meteorological Records}

In accordance with the sub-tropical nature of the climate, winter temperatures that reach the freezing point have been reported periodically in south Florida since 1766 (Johnson 1970 in Olmsted et al.1993). Typically, freezing temperatures last for no longer than 6-8 hours (Olmsted et al.1993). Ellis et al. (2006) reported temperatures of $-2^{\circ} \mathrm{C}$ for 8 hours in a mangrove community in Tampa Bay. When the drop in temperature occurs for consecutive days as it did in south Florida in December 1989, vegetation may be severely affected. While Cavanaugh et al. (2013) showed a strong relationship between rising temperature and mangrove forests expansion, the sudden collapse in mangrove forests density in particular years is often strongly correlated with freezing temperatures. In a 1995-2001 study, Ross et al. (2009) observed chilling damage in a dwarf mangrove forest in the study area on two occasions when temperatures dipped to $3^{\circ} \mathrm{C}$ or less (January 1996 and 2001), but not when minimum temperatures were higher. Hence, in this study I defined chilling events as periods in which temperature dropped to $3^{\circ} \mathrm{C}$ or less. For each event, I calculated "chilling degree hours $(\mathrm{CDH})$ " as a metric of event intensity; $\mathrm{CDH}$ was defined as the sum of the hourly degrees $\leq 3^{\circ} \mathrm{C}$ as shown in equation 1 .

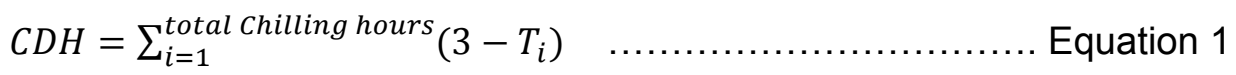

The frequency and duration of chilling events in the study area over the period 1985-2011 are illustrated in Table 1. The chilling temperature and duration of chilling temperature in 1996 January data was incomplete in meteorological 
records, however the event was documented and it's impacts on vegetation was reported by Ross et al. (2009). In this study, the meteorological station at Homestead Air Reserve Base (HARB), about $3 \mathrm{~km}$ from the study site, was chosen to determine chilling events. Meteorological records for HARB were obtained from the Weather Underground website (www.wunderground.com). Only records for the months December to February were examined, because chilling events have not been reported for other months.

\section{Satellite image processing}

Surface reflectance Landsat TM5 images were acquired from USGS via Earth Explorer http://earthexplorer.usgs.gov/ (Appendix 1). These images were standard level terrain corrected (L1T) products with no cloud cover over the study area. In addition to terrain correction, the images were already rectified for geometric and radiometric errors by the USGS. The L1T Landsat TM5 images were processed for the atmospheric correction through the Landsat Ecosystem Disturbance Adaptive Processing System (LEDAPS) (Masek et al. 2006, Vermote et al. 1997). This processing system used the $6 \mathrm{~S}$ radiative transfer approach to reduce noise from atmospheric scattering and absorption. Several recent studies on disturbances have used LEDAPS surface reflectance images (Zhu et al. 2012, Masek et al. 2008).

Sequential images have been used previously to detect changes in reflectance due to climate-driven factors (drought, flood) and natural disturbance (Behrenfeld et al. 2001, Lupo et al. 2001). Because chilling events cause abrupt changes in reflectance, these changes are detectable in remotely sensed images. Landsat 
images for this study were confined to the period between October and early April in order to detect changes driven by chilling events occurring in December through February. In images outside this period, change induced by chilling events becomes attenuated over time. An example is provided in Figure 2 a-c, which displays vegetation index images of the southern end of the study area (Blocks 3 and 4) from 1995, 1996 and 1997 respectively. Image differencing was employed to detect change due to the 1996 chilling event, which are essentially evident in Blocks 3 and $4\left(3^{\text {rd }}\right.$ and $4^{\text {th }}$ subdivisions within the outlined area in the Figure 1). The image in Figure 2(d) is the difference image between 1996 and 1995 and Figure 2 (e) represents the difference between 1997 to1995 vegetation index values. The spatial extent of change in Figure 2(d) is attenuated in Figure 2(e) with increasing time since disturbance. The difference image in Figure 2(f) shows recovery in several sections of the mangrove swamp after the event.

\section{Change Detection Algorithms}

Vegetation indices have been widely used in remote sensing to detect changes in forest ecosystems (Singh 1989, Nelson 1983, Coppin et al. 2004). The common indices applied in vegetation and disturbance studies are NDVI, NBR, SLAVI, and NDMI. These indices are widely used to detect changes in vegetation communities following fire, tree harvesting, drought, and defoliation (Schroeder et al. 2011, Luther et al. 1997, Spruce et al. 2011, Miller and Yool 2002, Healey et al. 2006, Lymburner et al. 2000, Masek et al. 2008). Because chilling events result in reflectance changes in Landsat image bands 3, 4, 5 and 7 as shown in 
Figure 3, which are represented in the above indices, I tested all four of them, plus a fifth index, DVI. The indices are discussed below.

\section{Vegetation Indices}

Normalized Difference Vegetation Index (NDVI) is the most commonly used index to measure the vigor of vegetation. The value of NDVI varies from -1 to +1 . NDVI for vegetation generally ranges between 0 and 1 , where larger values represent dense green forest. However, the NDVI values saturate at some point with increasing vegetation density (Lymburner et al. 2000). NDVI uses bands 3 \& 4 and calculated as follows:

$N D V I=\frac{\rho 4-\rho 3}{\rho 4+\rho 3} \ldots \ldots \ldots \ldots \ldots \ldots \ldots$ Equation 2

Specific Leaf Area Vegetation Index (SLAVI) was introduced to measure the specific leaf area of vegetation (Lymburner et al. 2000), thus its value is correlated linearly with leaf area index. It uses the bands $3,4 \& 7$ and calculated as follows:

$S L A V I=\frac{\rho 4}{\rho 3+\rho 7} \ldots \ldots \ldots \ldots \ldots \ldots \ldots$ Equation 3

Normalized Difference Moisture Index (NDMI): It was originally proposed by Gao (1996) to measure the moisture content in vegetation. It uses the bands 4 \& 5 and calculated as equation 4 . The index values vary from -1 to +1 , with high values associated with high water content in leaves. Wilson and Sader (2002) reported that NDMI performed better in detecting forest harvesting when compared to NDVI. 
$N D M I=\frac{\rho 4-\rho 5}{\rho 4+\rho 5}$

Equation 4

Normalized Burn Ratio (NBR) was developed to distinguish burned from unburned areas (Escuin et al. 2007). The assumption is that the moisture content in a burned area will be relatively low in comparison to an unburned area. Band 4 and band 7 are used for NBR calculation.

$N B R=\frac{\rho 4-\rho 7}{\rho 4+\rho 7}$ ...Equation 5

Difference Vegetation Index (DVI) was developed by Tucker (1979) for vegetation monitoring. The index uses bands $4 \& 3$ and computed as equation 6 . DVI is known to be indifferent to background variation common in mangrove forests (Diaz et al.2010).

$D V I=\rho 4-\rho 3$ Equation 6

After a chilling event, the biomass and leaf area of vegetation is reduced significantly, causing a difference in radiance value. Image differencing is a widely used method for detecting change at the pixel level (Coppin et al. 2004). In this approach, the vegetation index value of the Time 2 image is deducted from the index value at Time 1, as in Equation 7:

$\Delta V I=V I_{\text {time2 }}-V I_{\text {time1 } 1} \quad \ldots \ldots \ldots .$. Equation 7

The difference image returns a value range from negative to positive, and most unchanged pixels are near the center of a normally distributed set of pixels (Muchoney and Haack 1994, Coppin et al. 2004). Positive differences indicate an 
increase and negative differences indicate a decrease in index value. In this study, threshold value 1.25 standard deviation from the mean was applied to the lower tail of the distribution (Liu 1993, Ridd and Liu 1998, Macleod and Congalton 1998). Thus, pixel values less than the threshold value obtained from Equation 7 were considered impacted by chilling event. For each vegetation index, a change map was created from each image pair that bracketed a candidate $\left(\leq 3^{0} \mathrm{C}\right.$ at HARB) chilling event. The accuracy of change maps produced from equation 7 for years 1996, 2001 and 2010 were assessed by using field data, google earth engine, and visual interpretation. On the basis of these available data the region of interest (ROI)s were developed for impacted (change) and unimpacted (no change) areas as a sample ground truth. The region of interests (ROIs) used for chilling events 1996 and 2001 were developed by using 1996 field sample points with visual interpretation (Figure 4a). And, in case of 2010 chilling event, the ROls were made on the basis of google earth engine and visual interpretation (Figure $4 b$ ). On the basis of ROls as a ground truthing against the change map developed by employing equation 7 , I developed confusion matrices of change and no change pixels for 5 different indices change maps. The resultant Kappa-coefficient (K) and overall accuracy from confusion matrices were used as a basis to evaluate 5 indices (Mas 1999, Cakir et al. 2006). The index with the highest K-value and overall accuracy was selected as optimal for mapping change induced by chilling events from 1988 to 2011. The output map was filtered by using $4 \times 4$ pixel window to remove the salt-and-pepper effect evident in the raw change map. The spatial analysis of 
change maps of each chilling event were conducted to create the frequency distribution of chilling induced impacted area since 1988 to 2011 . I also did zonal statistics to see whether the changes induced by chilling events have significant effects on the mean index value of the study area as a whole, and to observe the trend of recovery pattern after each chilling event. The detailed analysis process of Landsat TM5 images to produce change induced area by chilling event is presented in Flowchart 1.

To compute the recovery rate from each different chilling event, I assumed the pre-event year NDMI value as a base year and calculated by using equation 8 .

$\% \Delta N D M I=\frac{\text { Mean } N D M I_{t+i}-\text { Mean } N D M I_{t}}{\text { Mean } N D M I_{t}} \ldots \ldots .$. Equation 8

Where, $i=1,2,3 \ldots$ successive image date after the chilling event $\mathrm{t}=$ date before the chilling event

Change maps were analyzed by using spatial analyst in ArcGIS 10.1 version (ESRI Inc, 2012). The change map produced by optimal index was used to create the patches of impacted area. The patch of impacted area were created by using conversion tool> raster to polygon in ArcGIS 10.1. I tested the distribution pattern of changed patches from each event by examining spatial auto-correlation via the Global Moran's I test in ArcGIS 10.1. By definition, a patch consisted of contiguous and adjacent cells of the same land cover i.e. impacted areas for this study. The minimum patch size is $120 \mathrm{~m} \times 120 \mathrm{~m}$. Patch metrics like mean patch size, frequency, fractal dimension, and Shannon's diversity index were calculated in FRAGSTAT 4.2. Patch metrics may provide 
insights on landscape patterns and resultant heterogeneity expected from disturbances. Fractal dimension is a metric to measure the shape complexity of patches present in a landscape (Burrough 1986). Similarly, Shannon's index reflects the diversity of patches of different land cover categories present in a landscape (Shannon and Weaver 1962).

\section{LiDAR Data Processing and Canopy Height Retrieval}

Mangrove forest in South Florida exhibits a strong structural gradient, featuring tall trees proximate to the coast and small trees inland. Previous reports on freeze damage documented severe damage in small trees in the interior zone. For example, Ross et al. (2009) documented that freeze damage was largely restricted to dwarf mangrove (see also Myers 1986). To examine more closely the association of canopy height and chilling effects, I used Light Detection and Ranging (LiDAR) data from the study area. LiDAR has been widely used in the study of forest attributes like canopy height, canopy density, and basal area (Andersen et al. 2006, Brandtberg et al. 2003, Wang and Glenn 2008, Lindberg et al. 2012, Wasser et al. 2013, Sexton et al. 2008, Lim et al. 2003). LiDAR data of 2007, from Florida Division of Emergency Management Coastal LIDAR Mapping Project was acquired and processed in ArcGIS 10.1 version (ESRI Inc, 2012).

By definition, tree canopy height is the vertical distance from the ground surface to the top of the canopy layer. Two different elevation models were created to determine canopy height, i.e., a digital surface model (DSM), and digital terrain model (DTM) as in Flowchart 2. These models employ the ground and last 
returns of the LiDAR data, respectively. The elevation models were created by using natural neighbor interpolation, and canopy height was computed as:

Canopy Height $(\mathrm{CH})=$ DSM - DTM Equation 9

The canopy height obtained was in foot unit system. The unit of the canopy was changed into the metric system by using conversion factor so that the unit of canopy height is same as change map produced from Landsat TM data. The conversion factor used was 0.3048006096 . The resultant canopy height map was resampled into $10 \mathrm{~m} \times 10 \mathrm{~m}$ cell size to test against field data obtained in 2003 , through sampling protocols described in Ruiz et al. (2002). 67 sampling points from blocks $6,7, \& 8$ were used for validation as shown in Figure 5 . Each sampling points is a $10 \mathrm{~m} \times 10 \mathrm{~m}$ plot oriented $\mathrm{N}$-S and maximum canopy height of each species was measured at $0 \mathrm{~m}, 5 \mathrm{~m}$ and $10 \mathrm{~m}$ along the centerline. The maximum canopy height of each species was averaged to calculate canopy height of $10 \mathrm{~m} \times 10 \mathrm{~m}$ plot.

\section{Field Data Collection}

Resampling of vegetation in several permanent monitoring plots was conducted subsequent to a series of chilling events in May 2013. Sampling plots were a subset of those established earlier to characterize vegetation structure in the Biscayne Bay Coastal Wetlands (BCW) (Ruiz et al. 2002). In 2002-03, Ruiz and collaborators divided BCW into 13 blocks, and sampled $226 \mathrm{~N}-\mathrm{S}$ oriented $10 \times 10$ $\mathrm{m}^{2}$ plots. Sampling was arranged in a nested design. To measure the shrub

density in each plot, 5 sub-plots of $1 \mathrm{~m} \times 1 \mathrm{~m}$ were established along the west of the central line at $0 \mathrm{~m}, 2 \mathrm{~m}, 4 \mathrm{~m}, 6 \mathrm{~m}$, and $8 \mathrm{~m}$ distance. Shrub density was recorded 
in two height categories, $60-100 \mathrm{~cm}$ and $100-200 \mathrm{~cm}$. Herb density was measured for each species in a $30 \mathrm{~cm} \times 30 \mathrm{~cm}$ quadrant located the southeast corner of the sub-plot. Seedling density was also measured in two categories; seedling height less than $30 \mathrm{~cm}$ and seedling height less than $30-60 \mathrm{~cm}$. Total cover and dead cover of dead material were recorded in each sub-plot. In May 2013, I used identical methods to resample 16 transects in Blocks 1, 2, 3, 4, 5, and 8 (Figure 1).

I also resampled a second set of monitoring plots initially established in 1996 (Ross et al. 2001; Ross et al. 2009) as shown in Figure 1. These plots were also $\mathrm{N}-\mathrm{S}$ oriented and divided into $901-\mathrm{m}^{2}$ sub-plots. Vegetation was surveyed in 10 sub-plots selected through a stratified random process. Live cover of each species, total live and dead cover, and mean and maximum height were observed in these plots in 1996-2001. I resampled the same subplots in May, 2013.

\section{Data Analysis}

Community response to chilling events was examined in non-metric multidimensional scaling (NMS) in PC_ORD 6 (McCune and Mefford 2011). NMS ordination is a powerful method to study community responses and their relationship to environmental gradients (Kruskal 1964, Minchin 1987, McCune and Grace 2002). The ordination was applied to data collected at the same plots in both 2003 and 2013. The data for ten $1-\mathrm{m}^{2}$ sub- plots were averaged to represent cover by species in each plot. Also, the plots were classified as 0 for no chilling event occurrence and 1 for chilling event occurrence on the basis of 
change maps produced. Species with less than 3 occurrences were removed from the data set, and cover data were standardized to the species' maximum values to reduce noise and increase the potential contribution of rare species to ordination (Faith et al. 1987). NMS with Sorensen (Bray-Curtis) distance was chosen, and the autopilot mode in PC_ORD 6 was used to determine the number of ordination axes required. Based on estimates of stress and the results of a Monte Carlo test it was decided that a 2-dimensional NMS was appropriate (McCune and Grace 2002). Monte Carlo test simulates the data for number of runs to get the probability distribution and determine whether it is random or not (McCune and Grace 2002).

To determine if the species composition in chilling-impacted and unimpacted areas differed, a non-parametric multi-response permutation procedure (MRPP) was used in PC_ORD 6 (Mielke 1984, McCune and Grace 2002). $30 \times 30 \mathrm{~m}^{2}$ plot data was used for MRPP analysis for different years 1997, 1999, 2001 and 2013. The data collected from Block 1 was considered as control (or No Chilling) and Block 4 was considered treatment (or Chilling). The parameters employed in MRPP analysis were the Sorensen (Bray-Curtis) distance with natural weighting, as recommended by Mielke (1984). MRPP provides within group homogeneity (agreement statistic (A)) in species space, and a p-value (probability of smaller or equal delta). The delta is the weighted mean within group distance (McCune and Grace 2002). In addition, I performed indicator species analysis (Dufrene and Legendre 1997) to identify major indicator species for chilling 'impact' and 'no impact' sites across different years $(1997,1999,2001,2013)$ by using $30 \times 30 \mathrm{~m}^{2}$ 
plot data in PC_ORD 6 (McCune and Mefford 1999). Indicator values for each species were computed using the indicator species analysis module in PC_ORD 6. The statistical significance of such indicator values was tested using a MonteCarlo permutation test with 10,000 random permutations. In addition, the Shannon-Weiner index of diversity (Shannon and Weaver 1949) was calculated to measure species diversity. It is sensitive to rare species and estimated mathematically as:

$H^{\prime}=-\sum_{i=1}^{S} p_{i} \ln p_{i}$ Equation 10

Where,

$S=$ total number of species

$\mathrm{p}_{\mathrm{i}}=$ proportion of all individuals in a sample which belong to species $\mathrm{i}$.

The value of $H^{\prime}$ for communities range from 0 for a community with no diversity to values around 5 for extremely diverse communities, though mangrove vegetation rarely reaches such levels.

\section{Results}

\section{Disturbance Maps}

The effectiveness of the five indices in reflecting damage from the 1995-96, 2000-2001, and 2010-2011 chilling events are depicted in Table 2. The common vegetation indices (NDVI, SLAVI, and DVI) didn't perform well in detecting change induced by the chilling events of 1995-96 and 2000-2001. I had speculated that leaf area indices would show phenomenological change after the chilling event, thereby presenting a sharp decline in the index value. However, despite the generally high accuracy of these indices, they had low K-coefficients, 
indicating error of misclassification. Accuracy was highest for the 2010 event. Among all the indices SLAVI exhibited consistently lower accuracy in all events. NBR and NDMI indices produced similar and consistent result in the 1995-96 and 2010-11 events, with relatively high K-coefficients. These two indices use Landsat TM Bands 5 and 7 , which are sensitive to any disturbances in the forest. The NBR index has been previously used to measure the disturbance in forest stands, especially from fire (Miller and Yool 2002). Based on the data I examined, NDMI was the best index for detection of change induced by chilling events, despite its low K-coefficient (0.14) for the 2000-2001 event. The lower accuracy might be due to attenuation in the index value, as the time period between image pairs available for analysis was longer than for most other events. However, its ability to detect change from the 2000-2001 event is notable, since this event as not as severe in effect as the 1995-96 event (Ross et al. 2009), and did not reach as low a temperature (Table 1).

Bi-temporal NDMI image differencing was used to map the change induced by chilling events 1989, 1996, 2001, 2009 February, 2010 January and 2010 December (Figure 6). A final disturbance map representing the change induced by all chilling events over time and space was created (Figure 7). The total area that was disturbed at least one time is $29.8 \%$ since 1989 in 6 different chilling events. Because the study area has been influenced frequently by chilling, the final change map was classified into three categories on the basis of frequency of chilling over the area. If the chilling event occurred more than three times in same area it was classified as highly disturbed; areas disturbed 2-3 times over 
the study period were classified as moderately disturbed, and those disturbed only once were categorized as lightly disturbed. Most of the southern parts of study area were highly disturbed by chilling events.

\section{Spatial distribution of chilling events}

The spatial distribution of patches impacted by each chilling event were analyzed to identify whether the distribution was random or clustered. We found the $p$ value from Global Moran I test has less than 0.05 for each event within $1500 \mathrm{~m}$

threshold distance. The p-value obtained from the statistical test implied that the distribution pattern of impacted area was clustered at $1500 \mathrm{~m}$ threshold distance. Further analysis of patch size, number of patches and fractal dimension was conducted, and results are presented in Table 3. The largest mean patch size and lowest number of patches were found in the 1989 chilling event. Although the temperature reached in the 2001 chilling event was not as low as in the 2010 December chilling event, the mean patch size impacted and number of patches in the two events were similar; these events were second in severity to 1989. The fractal dimension of patch in each event had similar value representing less complexity of patch perimeter i.e. likely a square in shape (Burrough 1986, Turner 1990). The result from Shannon's diversity index of each event was consistent with severity of chilling event. The highest diversity (SHDI=0.36) was observed in 1989 and 2010 December events, and the landscape diversity associated with the 2001 event was much lower (0.23). 


\section{Trajectory of Vegetation Index}

Mean NDMI was calculated from 1988 through 2011 (Figure 8). The change in NDMI reflected the disturbance in the study area over the years. Mean NDMI decreased after 1989 chilling event up until April 1990. In 1991, it started to recover. This trend of declining NDMI four months after 1989 freeze is indicative of the great severity of the 1989 freeze event. The study area was again hit by Hurricane Andrew in August 1992, which led to a sharp decline in NDMI followed by a recovery over a 2-3 year period. In general, the trend of disturbance and recovery is evident throughout Figure 8, with the years 1989, 1992, 1996, 2001, 2009, 2010 and 2011 initiating each cycle. However, the 2003 chilling event was not show up in mean NDMI graph because the temperature dropped in February of 2003 and the available image used in this study was obtained in January 2003. Similarly, NDMI was not able to identify the 2008 chilling events, possibly due to the long duration between the chilling events and the post-event images used for NDMI calculation. Figure 8 also suggests that the rate of decrease in index depends on the number of chilling events in successive years, image acquisition date before and after the event and the duration of chilling temperature. Sometimes, even a short-duration event may be evident in a NDMI decrease. A prime example is a February 2009 event in which temperature dropped for to $2.7^{\circ} \mathrm{C}$ for one hour $(\mathrm{CDH}=0.3)$. The event was bracketed closely by TM images, and an NDMI decrease of $12.58 \%$ was noted. The rate of decrease in mean NDMI was more than 25\% in 1989, 1996 and 2010 December chilling events. 
The \% change in mean NDMl compared to a base year was used to track mangrove forest responses to disturbances, including both freeze events and hurricanes. During the 1989 chilling event, also known as the Christmas freeze, $\mathrm{CDH}$ totaled 31 hours in two consecutive days in south Florida. Figure 9 shows the trend of vegetation recovery from the 1989 freeze event. The rate of recovery was calculated by using equation 8. When 1988 November image was considered a base year, the NDMI decline in impacted area was $56 \%$, which suggests severe impact of freeze event on mangrove forest. After 1990, the decline in NDMI compared to the base year started to decrease. This trend suggests that these forests started to recover from the impacts of 1989 chilling event after 1990. However, the sudden decrease in the percentage NDMI change from base year in 1993 was primarily due to the effect of Hurricane Andrew. It took almost 7 years for the vegetation to recover to the conditions prior to the base year (pre 1988 condition) (Figure 9). However, vegetation recovered quickly after the 1996 chilling event compared to 1989 event (Figure 10). It is likely that extended recovery period after the 1989 event was due to the effect of Category 5 Hurricane Andrew in 1992 August. Although the recovery of vegetation after the 2001 chilling event was slower compared to the 1996 event, the more extended trajectory was likely due to the effect of successive chilling event which occurred in 2003 (Figure 11). Because suitable images after a chilling event 2003 were not available, the effects of that chilling event were not detected in November 2003 NDMI image, possibly due to recovery of mangrove after 10 months. A study by Steven et al. (2006) reported that black mangroves 
recovered within six months after a chilling event. Nevertheless, the intensity, frequency, and duration of the chilling event dictates the recovery period of mangrove forests.

\section{Relationship between the chilling events and canopy height}

As expected the LiDAR estimation of canopy height of the study site showed a gradient in height class (Figure 12a), with tall canopy fringe trees closest to the coast and height decreasing sharply towards the inland. Also, small tree islands with slightly taller canopies were sparsely distributed in the dwarf mangrove forest. In the dwarf mangrove forest, tall canopy height trees alongside the road and ditches created broad canopy depressions at distance from these landscape features. Regression analysis between field estimates of height and LiDAR estimates showed a strong and significant linear relationship $\left(R^{2}=0.89\right.$, Figure 13). The LiDAR data showed an overestimation, probably because the field data was collected in 2002 while the LiDAR data was collected five years later. Because the rate of mangrove tree growth depends on the composition of mangrove forests and the productivity of the site, overall tree height gain during the period from 2002 to 2007 may different with species and physiographic zone. For example, trees growing in forests fringing the coast have a higher rate of growth due to their high productivity when compared to dwarf forests of the interior (Ross et al. 2002). In addition, the precision and accuracy of canopy height estimation depends on the geographic location of plots, laser point density, and the number of returns (Lefsky et al. 2002). These factors led to deviation from a perfect 1:1 relationship between observed tree height and 
estimated LiDAR height. Nevertheless, the estimated canopy height from LiDAR data was a reliable measure of tree height.

Recent chilling events $(2008 / 09,2009 / 10,2010 / 11)$ were used to assess how chilling impacts varied among forests of different stature (Figure 12b, Figure 14). Generally, chilling events influenced plant communities of lower canopy height. $50 \%, 25 \%$, and $48 \%$ of the forests of canopy height $<2 \mathrm{~m}$ were affected by the chilling events of 2009, 2010 January, and 2010 December respectively. In contrast, chilling damage in forests $4 \mathrm{~m}$ tall or taller in the same events were $1.3 \%, 5 \%$ and $3 \%$. When the different chilling events were compared, the 2010 January chilling event had a larger effect among the taller tree classes than 2009 and 2010 December chilling events. The extent of damage in different canopy height classes appeared to be related to the minimum temperature reached and the duration of the chilling events. For example, the temperature dropped for $\mathrm{CDH}$ totaled 0.28 hours in Feb 2009 , affecting just $1.4 \%$ of trees greater than 4 m. However, when the temperature dropped for total $29.33 \mathrm{CDH}$ in 2010 in two consecutive days in $10^{\text {th }}$ and $11^{\text {th }}$ January, it affected almost $7.2 \%$ of similarsized trees. In December 2010, the temperature reached chilling temperature for $\mathrm{CDH}$ totaled 10.6 hours but in three different days. The analysis of chilling events and impacted area in each class height suggest that tall trees might be damaged if the freezing temperature occur for relatively long periods, but intermittent shortduration chilling causes damage only in low canopy forests. 


\section{Community Response to Chilling Event}

The response of vegetation in the study area to chilling events was not directional. The NMS ordination showed that "no impact" sites were clustered while "chilling impacted" sites exhibited more variation in composition (Figure 15). Among the three major species, red mangrove had a strong positive relationship to ordination axis $1(r=0.581)$ (Figure 16a). Because red mangroves are the least tolerant of the resident tree species to chilling events (Markely et al. 1982), they are more abundant in no-impact sites when compared to sites affected by chilling. This is supported by the strong negative correlation $(r=-0.561)$ of chilling effect with axis 1 . On contrast, white mangroves were distinctly clustered in ordination space in both chilling-impacted and unimpacted sites (Figure 16b). Although white mangrove is not hardy to chilling, they often recover rapidly by sprouting after the event. This is partly supported by the strong negative correlation of white mangrove with ordination axis $1(r=-0.769)$.

Results from MRPP analysis also showed a clear compositional distinction between chilling impacted sites and unimpacted sites (Table 4) at all chilling events.

Only statistically significant results of indicator species analysis are presented in Table 5. Red mangrove was the major indicator of no impact sites especially for the year 1997 and 2013. After severe chilling events in 1995/96 and 2010/11, red mangrove species likely died in the chilling impacted sites, and likely did not recover to former levels of abundance in chilling impacted sites within two years after the event. The consistent absence of red mangrove in chilling impacted 
sites and consistent presence in unimpacted sites during 1997 and 2013 is likely the reason for this species being an indicator in only these years. Philoxerus vermicularis, associate species with black mangrove presence in chilling impact sites was significantly present in impacted sites in all years. Black mangrove was an indicator of chilling impacted sites with high indicator values in 1999, 2001, and 2013 with high indicator values (Table 5). Similarly pioneer species like Sesuvium portulacastrum, Rhabdadenia biflora, and Conocarpus erectus were all observed in chilling impacted sites. In unimpacted sites, the presence of the saltmarsh grass Distichlis spicata was noted in 1999 and 2001. The observation of the halophytic, disturbance-responsive vines Rhabdadenia biflora and Philoxerus vermicularis in unimpacted sites during the 2013 vegetation survey indicates that the sites might were disturbed to some extent during 2010 December chilling events. Also, the analysis of Shannon's diversity index showed that chilling impacted sites had relatively high species diversity when compared to unimpacted sites (Figures 17). The high species diversity and richness in chilling impacted sites was consistent over all years. Our result here is consistent with the general notion that the diversity is higher at disturbed sites (Connell 1978).

\section{Discussion}

\section{Remote sensing and chilling event}

Remote sensing has provided an important tool to define and understand change in natural ecosystems at various scales. The property of change in specific spectral bands before and after a disturbance event is utilized to detect 
environmental change. Attempts to describe these relationships have lead to the development of many specific indices. As shown in Figure 2, the big difference in the spectral reflectance from specific bands before and after the 2010 chilling event are reflected differently in indices like NDVI, NDMI, NBR, \& DVI. For example, Escuin et al (2008) found that the NBR index was better at detecting the impacts of fire than NDVI, because it employs Bands 4 and 7 . Band 7 is sensitive to soil moisture content, which often decreases after a burn. However, because soil moisture differs little among variously flooded or saturated mangrove soils. NBR was less effective in detecting change resulting from the 2001 chilling event in our study. My analysis of the spectral indices indicated that NDMI was best at detecting change induced by chilling events in mangrove vegetation, due to the index's inclusion of Band 5 . Because Band 5 is sensitive to the moisture content of the leaf, the successive drying of leaves following a chilling event is reflected in the index value. Other studies have also found NDMI to be useful in detecting disturbance effects. Wilson and Sader (2002) used NDMI to detect partial harvest in forests. Similarly, Townsend et al. (2012) took advantage of Band 5's properties to detect insect damage in forests. Hence, the NDMI index is optimal in detecting changes induced by disturbance, especially when canopy cover has not been completely removed.

The accuracy of mapping changes induced by chilling events also depends on the temporal resolution of the relevant imagery. The impacts of some disturbances, for instance, hurricane and wildfire are persistent and can be detected on Landsat images even 1 or 2 years after an event. However, the 
detectability on satellite imagery of damage from cold temperature might last from a few months to a few years following the event, depending on the severity of chilling. Beginning with the onset of chilling temperatures during December to January, leaf desiccation and extent of damage continues until March and sometime extends to April. In my study area, the severity of damage to mangrove forests was reflected in declining mean NDMI. For instance the continue decrease in mean NDMI of the study area continued to decline through the April 1990 image i.e. 4months after the disturbance. A similar observation was documented by Lugo and Zucca (1977), who reported that damage was more severe in early April than in February following a January 1977 freeze event in Sea Horse Key, Florida. Once mangrove damage from chilling temperature approaches peak during March, it starts to recover i.e. the mean NDMI value in the year following a chilling event usually increases. For instance, the study area's mean NDMI value increased in 2002 Feb after the chilling event of 2001 (Figure 8). Hence, the spatial extent of damage from 2001 chilling event could not be assessed with higher accuracy by using 2002 February and 2000 January images. The attenuation effect of time in spectral change is due to the vegetation recovery after chilling events as shown in Figure 2 . This might be the reason that chilling events in 2003 and 2008, which had long intervals between pre- and post event images, were not detected in the image differencing method I used. Similarly, reoccurrence of chilling events in successive winters e.g. in January of 2010 and again in the following December, also confound the accuracy of spatial change maps. Wilson and Sader (2002) suggested that image differencing by 
acquiring Landsat images at 1 or 2 year intervals is optimal for detecting partial harvesting in forests with high accuracy. Our results and method of change induced mapping is also consistent with Spruce et al. (2011), who documented that insect defoliation can be detected with higher accuracy using a single date image differencing method in comparison to multi-date composite image differencing of MODIS data. Our analysis suggests that change induced by chilling events is best detected if images bracket the period November - March.

The distribution of chilling impacted patches is spatially different in following different chilling events. However, some impacted patches are overlap and/or extend areas affected by previous chilling events. In different chilling events between 1989 and $2011,29.8 \%$ of the total area was impacted at least one time. If the current regime of chilling events continues, then the study area would get impacted by at least one chilling event in every 107 years. However, the probability of occurrence of chilling events is susceptible to change as a global temperature increases.

Patch-scale variation in mangrove canopy structure may have contributed to the inverse relationship between tree height and chilling damage observed in my study. For instance, Ewers and Banks-Leite (2013) found sharp variation in day and night temperature in fragmented patches, while adjacent closed canopy forests exhibited less variation. Similar patch-scale variation in temperature may occur in my study site, where differences in tree height create micro-climate variation between the dwarf and adjacent fringe forests. The relatively high diurnal temperature in dwarf forests (Ross et al. 2009) exacerbates the radiative 
chilling during clear and calm winter nights. The resultant cold air sinks in localized canopy depressions, i.e., dwarf mangrove basins which are surrounded by coastal fringe forest or by tall trees occupying the levees along canals and ditches. This might be the reason that damage from chilling events was generally confined to dwarf mangrove trees (Figure 14). Also, another constraint is that the proximity to ocean and frequent surface water may moderate cold temperatures within fringe forests, a condition which is absent in the dwarf mangrove forest. However, all these assumptions implicitly depend on the physiological function of trees. In this regard, Leslie et al. (2014) documented that large trees exhibited less cold damage than smaller neighbors in eucalyptus forests. Similarly, Lugo and Zucca (1977) recorded impacted tree size up to $4 \mathrm{~m}$ during 1977 chilling event in Sea Horse Key, Florida. From our analysis of an event in which chilling temperatures were reached in three successive nights in January 2010, trees from $2 m$ tall up to $8 m$ tall were affected. During this sequence, total $\mathrm{CDH}$ was 29.33 hours, and the minimum temperature reached was $-0.61^{\circ} \mathrm{C}$, making this the most severe chilling period since December 1989. Hence the spatial relationship between damage and tree height appears also to be a function of minimum temperature and duration.

\section{Chilling impacts on mangrove community}

The responses of mangrove species vary. Among the three major mangrove species of the study area, red mangrove is most sensitive to chilling. After chilling events in 2001 and 2010, the abundance of red mangrove was declined more severely than did black mangrove. These vegetation responses to cold 
temperature parallel those described elsewhere. McMillan \& Sherrod (1986) documented that black mangrove can tolerate freezing temperature. The lower sensitivity of black mangrove to chilling temperatures allow its distribution to extend farther north in comparison to other mangrove species (Kruass et al. 2008). Also, Markely et al. (1982) reported that red and white mangroves are more sensitive than black mangroves to chilling. The relative sensitivities of mangrove species to chilling events ultimately lie in their physiological function. Mangrove lose conductivity during chilling events consequently causing damage to xylem vessels. According to Stuart et al. (2006), loss of hydraulic conductivity is a function of vessel diameter and density. Due to the smaller vessel diameters and shorter vessel elements characteristics of black and white mangroves in comparison to red mangrove (Yanez-Espinosa and Flores 2004), the former two species appear to experience a reduction in chilling induced embolisms. Red mangrove species loses $60-100 \%$ of hydraulic conductivity under freeze and thaw tension (Stuart et al. 2006), and thereby suffers mortality. In contrast, black mangroves show quick recovery after severe chilling event (Stevens et al. 2006). As canopy gaps are created by damage or mortality among any of these species after chilling events, nutrients and light availability are enhanced, and the establishment of pioneer species follows. Hence, plant species diversity is enhanced in such gaps in comparison to unimpacted sites. While species dominance in chilling impacted sites depends on the recovery rates of species, local sources of propagules also influence species dynamics. The repeated 
occurrence of chilling events would likely enhance coastal mangrove biodiversity at small scales.

\section{Conclusion}

Repeated chilling events are ecologically important in maintaining the structural dynamics of mangrove forests at a patch level within a landscape. Mapping the spatial distribution of such patches at large scales over time is possible with remote sensing tools. Among the vegetation indices tested, NDMI is the most effective in delineating the spatial distribution of change induced by chilling events. However, the accuracy of such maps is influenced importantly by the temporal resolution of the remote sensing data. To capture the chilling event, images dated November and March are appropriate to bracket chilling events that are limited to the December-February period in south Florida. Spatial and temporal distributions of chilling induced change maps provide good insights toward understanding this disturbance regime. The spatial locations of areas affected by a series of chilling events did not overlap perfectly i.e. some patches were extended in successive events. The frequency of chilling events since 1988 has shown no reduction, especially in the southern part of the study area, despite the prediction of reduced chilling events in the current climate change scenario (Cavanaugh et al. 2013). Based on canopy heights obtained from LiDAR data, I concluded that most chilling induced changes were confined to dwarf mangrove forests $(<2 \mathrm{~m}$ tree height). The spatial distribution of these impacts creates the mosaic of patches in the dwarf mangrove forest helping to maintain heterogeneity at the landscape level. In addition, the recovery from these 
disturbances depends on their frequency and intensity. In the absence of subsequent disturbances (including hurricanes), chilling impacted generally recovered within 3 years, as best exemplified by recovery after the 1996 event. Change in community composition following chilling events depends to some extent on the disturbance. The repeated occurrence of severe chilling events appears to be capable of converting community composition from the current red mangrove dominated dwarf forest to one in which white mangrove, black mangrove, and buttonwood prevail, as previously suggested by Ross et al. (2009). My data showed also the emergence of herbaceous species such as salt grass, bladderwort, and mangrovevine species in chilling impacted areas, denoting an increase in species diversity. However, if chilling events are important in maintaining structural and compositional diversity within mangrove forests. A reduction in their occurrence in response to globally increasing temperature portends a decrease in this local heterogeneity as well as a potential expansion northward at the expense to salt marsh (Stevens et al. 2006). As chilling events become less frequent and intense in the future, tall homogeneous red mangrove forests may become more prevalent in North American coastal wetlands. 


\section{Appendix 1: List of LEDAPs Images}

\begin{tabular}{|ll|}
\hline \multicolumn{2}{|l|}{ LEDAPs Imagery Date } \\
$11 / 18 / 1988$ & $2 / 18 / 2002$ \\
$12 / 31 / 1989$ & $1 / 20 / 2003$ \\
$4 / 6 / 1990$ & $11 / 24 / 2003$ \\
$1 / 20 / 1991$ & $1 / 23 / 2004$ \\
$10 / 20 / 1992$ & $11 / 28 / 2006$ \\
$3 / 29 / 1993$ & $1 / 31 / 2007$ \\
$4 / 1 / 1994$ & $2 / 3 / 2008$ \\
$3 / 19 / 1995$ & $11 / 17 / 2008$ \\
$11 / 14 / 1995$ & $2 / 5 / 2009$ \\
$3 / 21 / 1996$ & $10 / 19 / 2009$ \\
$1 / 3 / 1997$ & $2 / 8 / 2010$ \\
$11 / 6 / 1998$ & $10 / 22 / 2010$ \\
$12 / 27 / 1999$ & $2 / 27 / 2011$ \\
$1 / 12 / 2000$ & $11 / 10 / 2011$ \\
$3 / 3 / 2001$ & \\
\hline
\end{tabular}




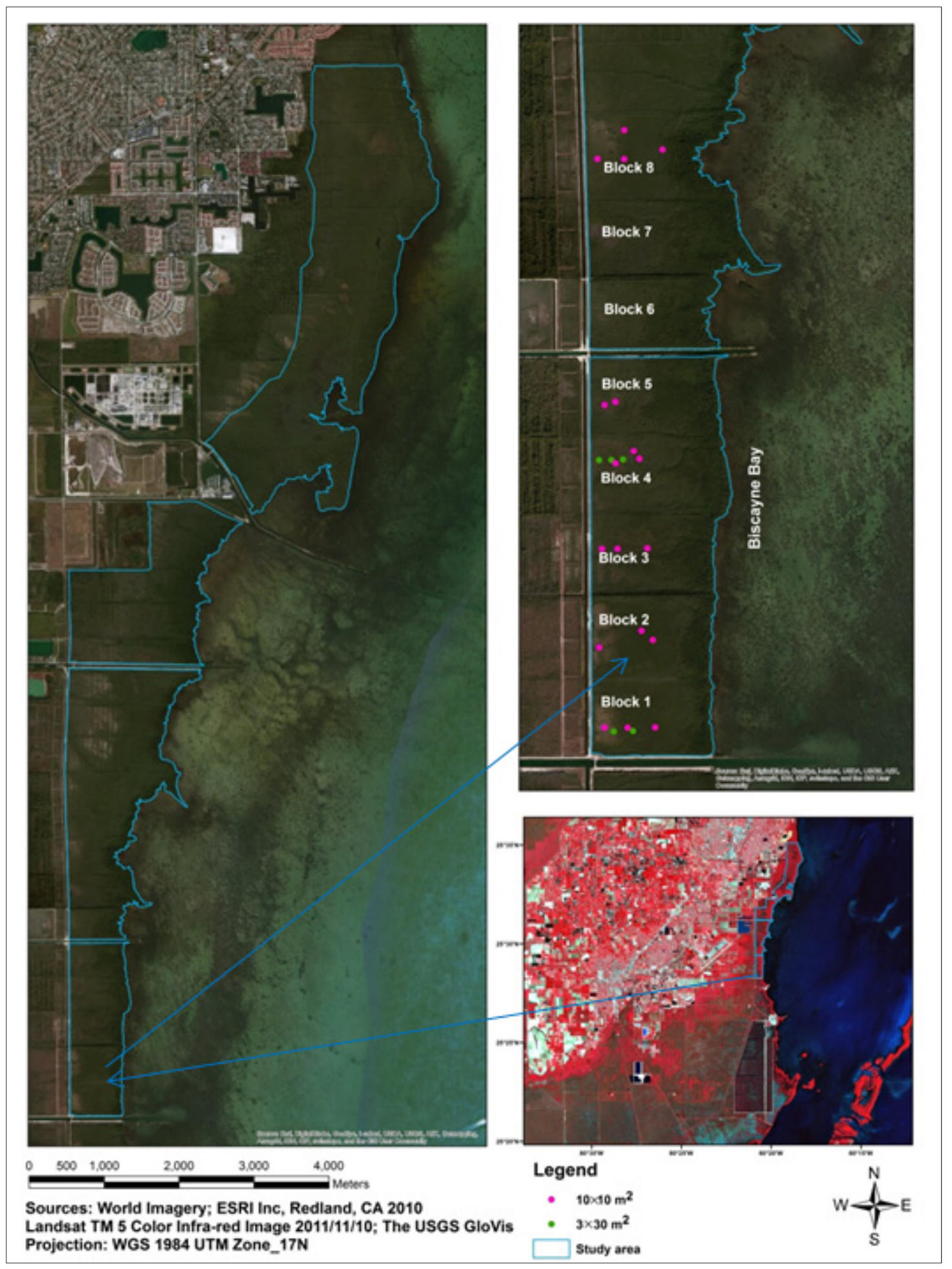

Figure 1. The study area (Biscayne Bay), Florida, USA with sample plots layout in different blocks. 


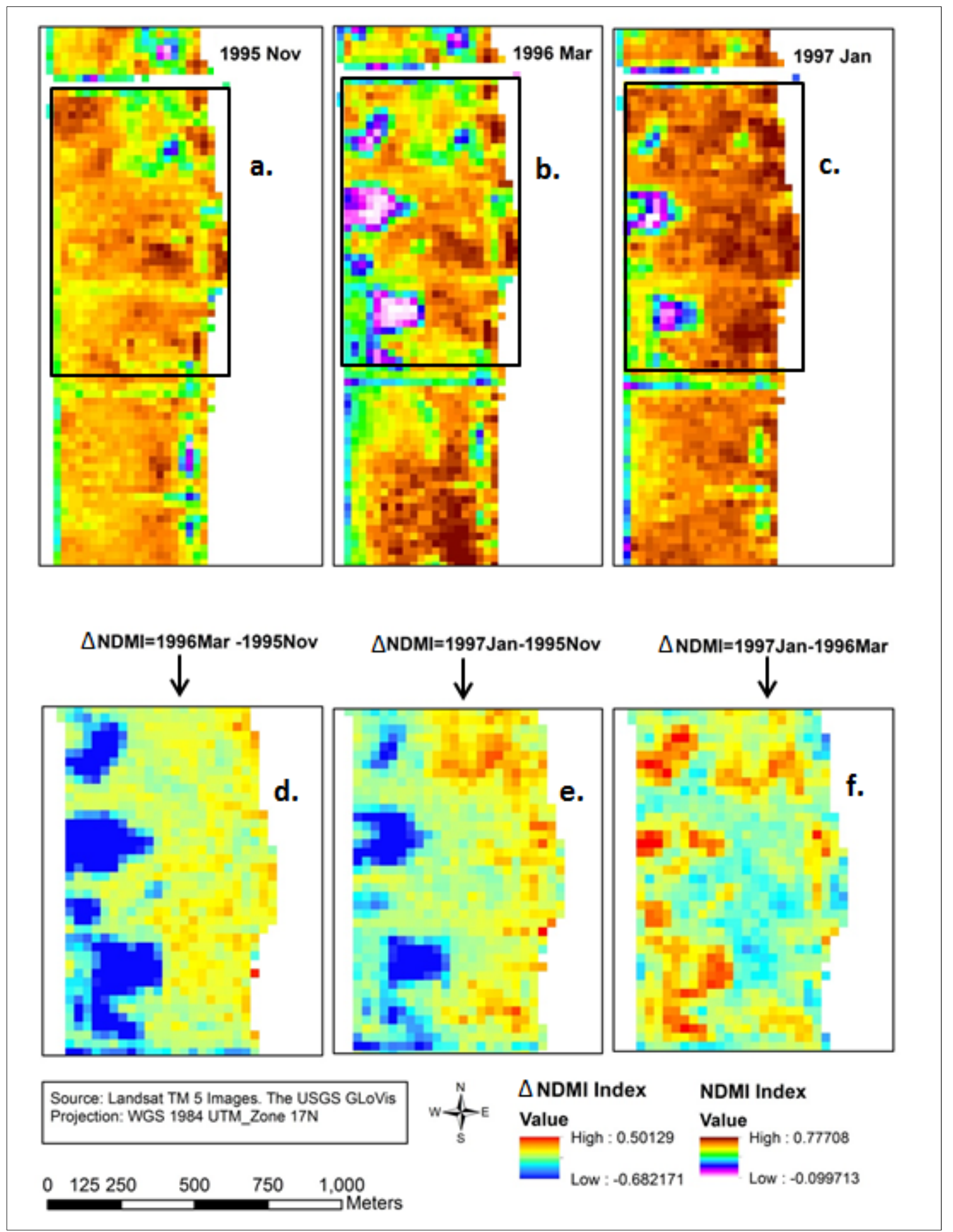

Figure 2. Effects of temporal resolution in detecting change induced by chilling events in blocks 3 and 4 of the study area as shown in Figure 1. 


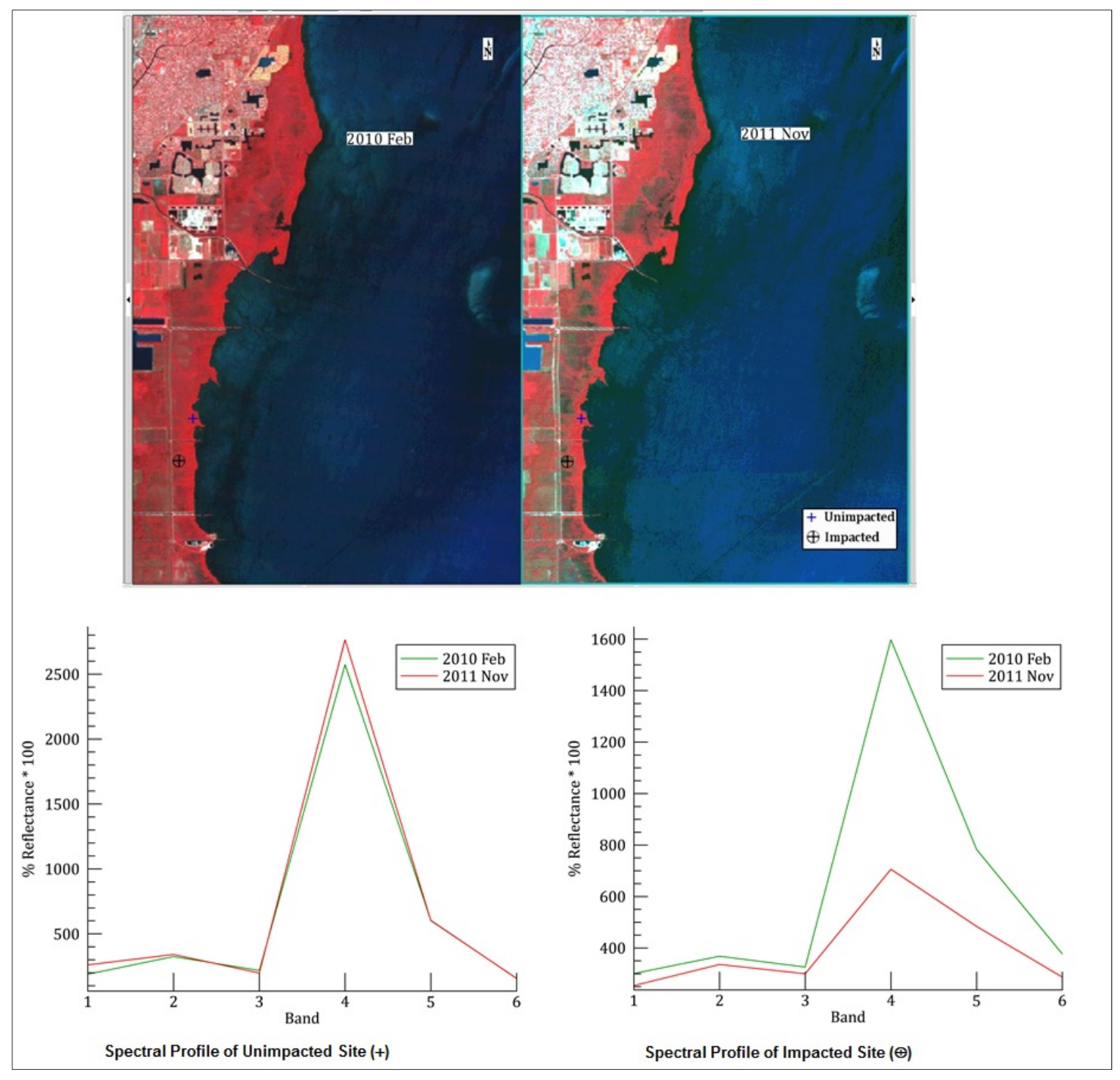

Figure 3. Spectral profiles of chilling impacted and unimpacted sites after 2010 December freeze. 

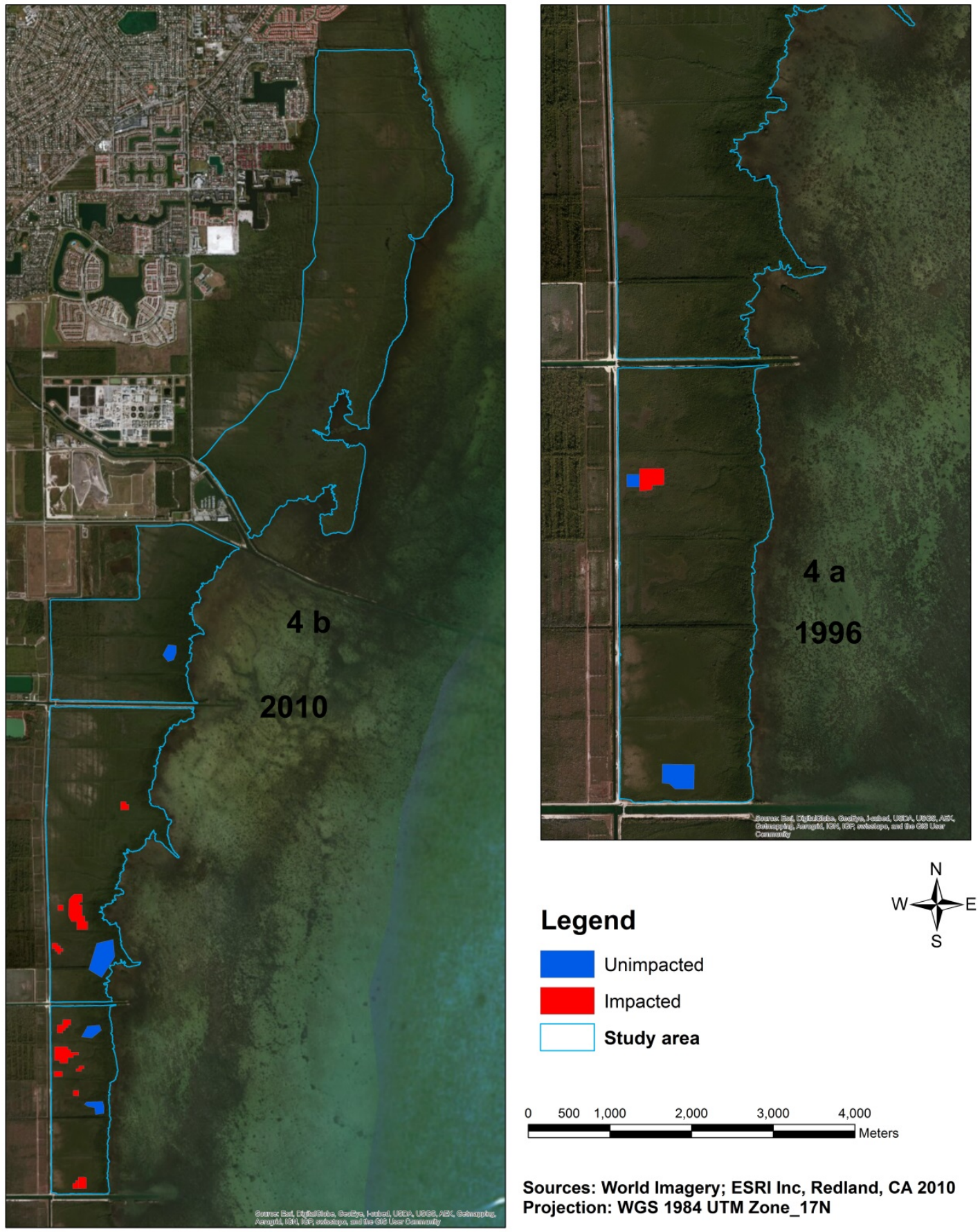

Sources: World Imagery; ESRI Inc, Redland, CA 2010 Projection: WGS 1984 UTM Zone_17N

Figure 4. Region of Interests (ROIs) used as ground truthing in confusion matrix. 


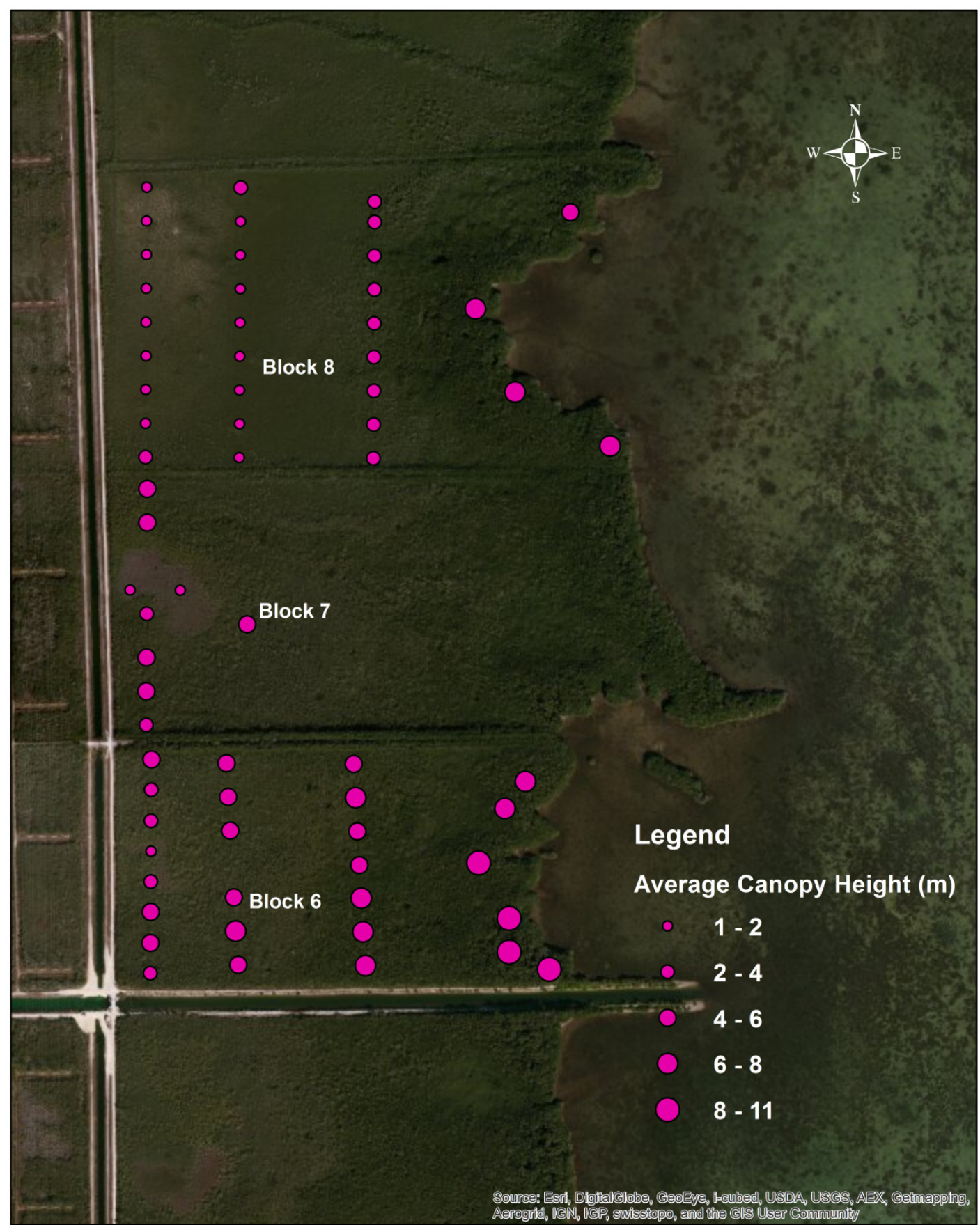

Source: World Imagery, ESRI Inc, Redland, CA 2010 Projection: WGS 1984 UTM Zone_17N

Figure 5. Field sample plots used to test canopy height estimated from LiDAR. Field canopy height was measured in 2003. 

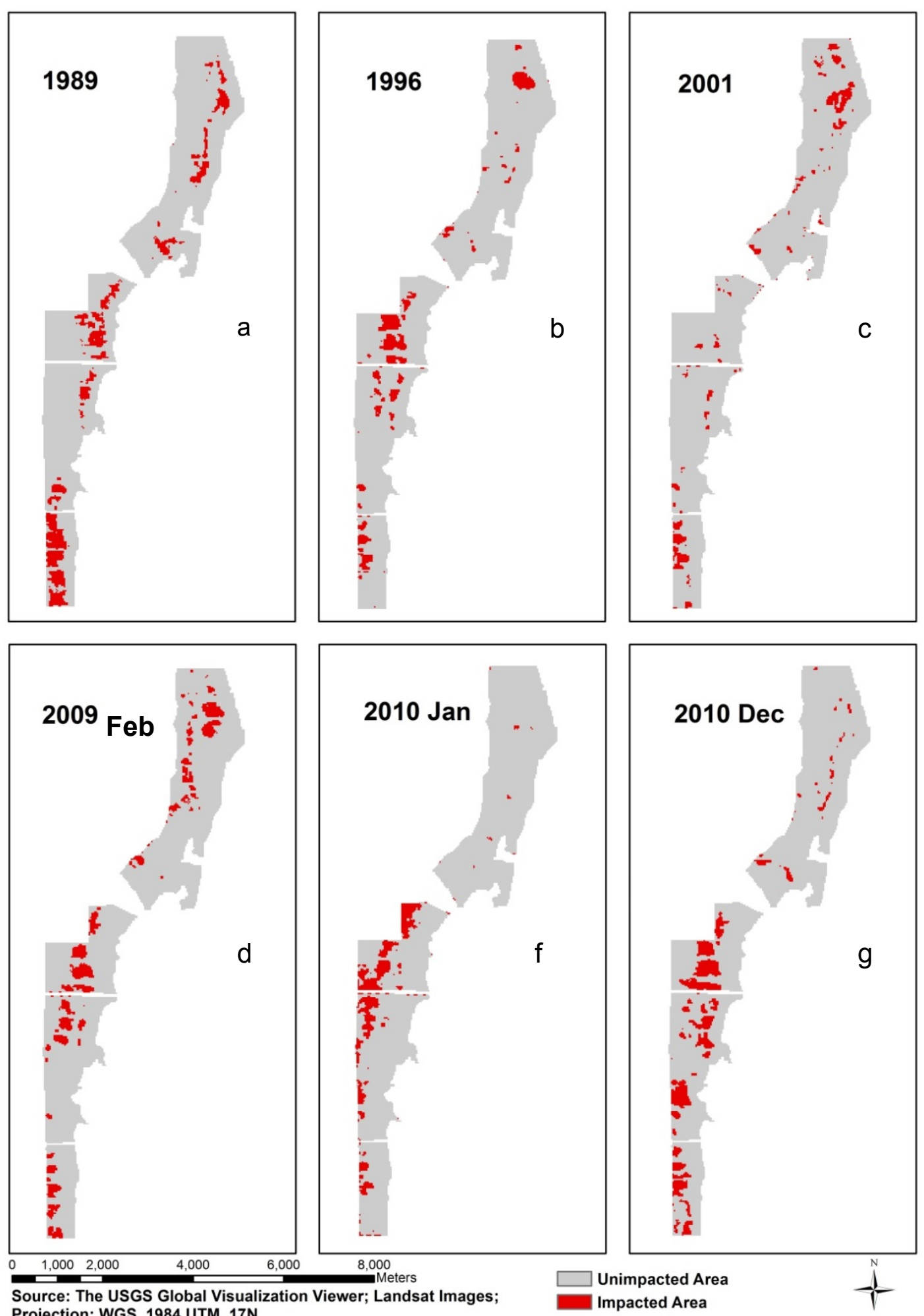

Projection: WGS_1984 UTM_17N

Figure 6. Chilling induced impacted area in different chilling events. 


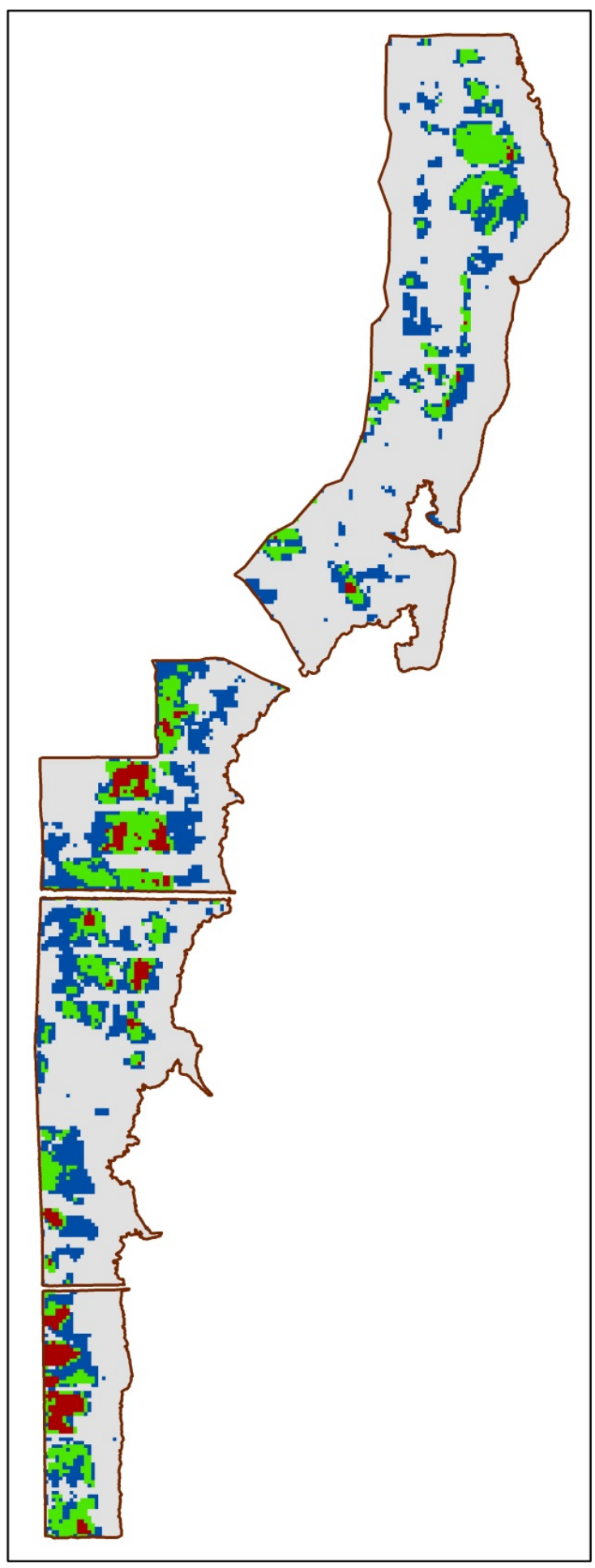

-

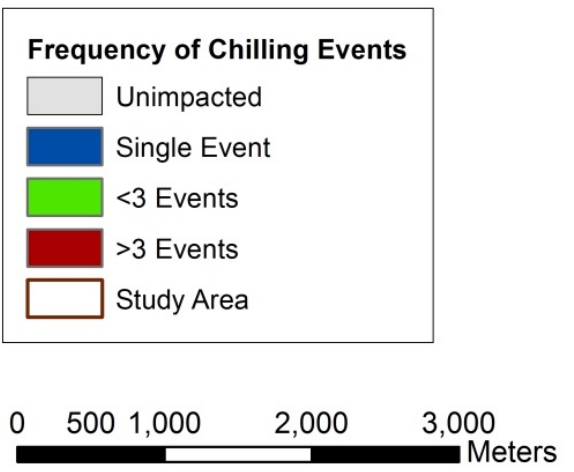

Source: The USGS Global Visualization Viewer (GloVis);

Projection: WGS_1984 UTM_17N

Figure 7. Frequency distribution of chilling induced change area since 1988. 


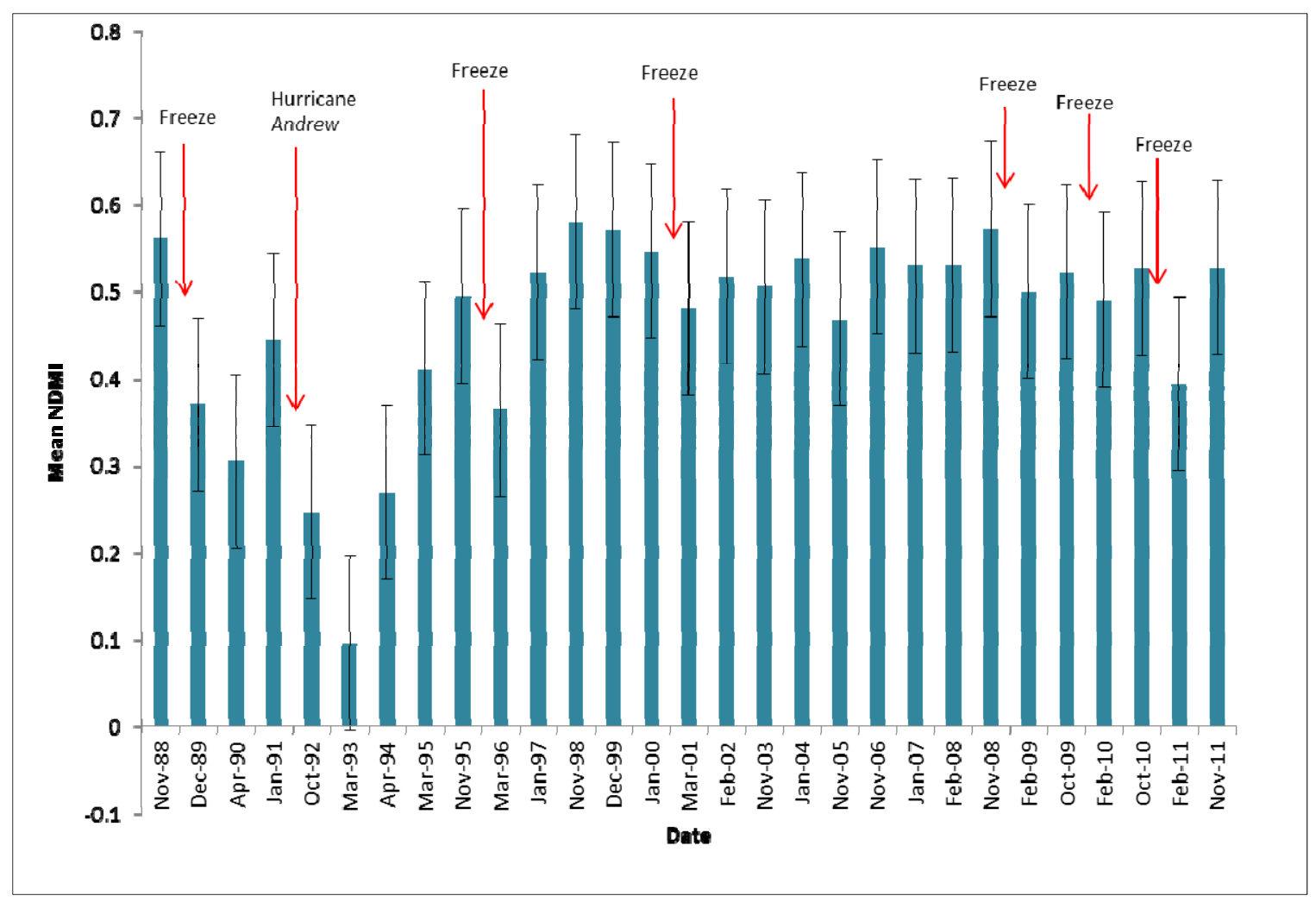

Figure 8. Trajectory of mean NDMI index of the study area since 1988 to 2011 . The vertical bar represents the standard deviation from the mean.

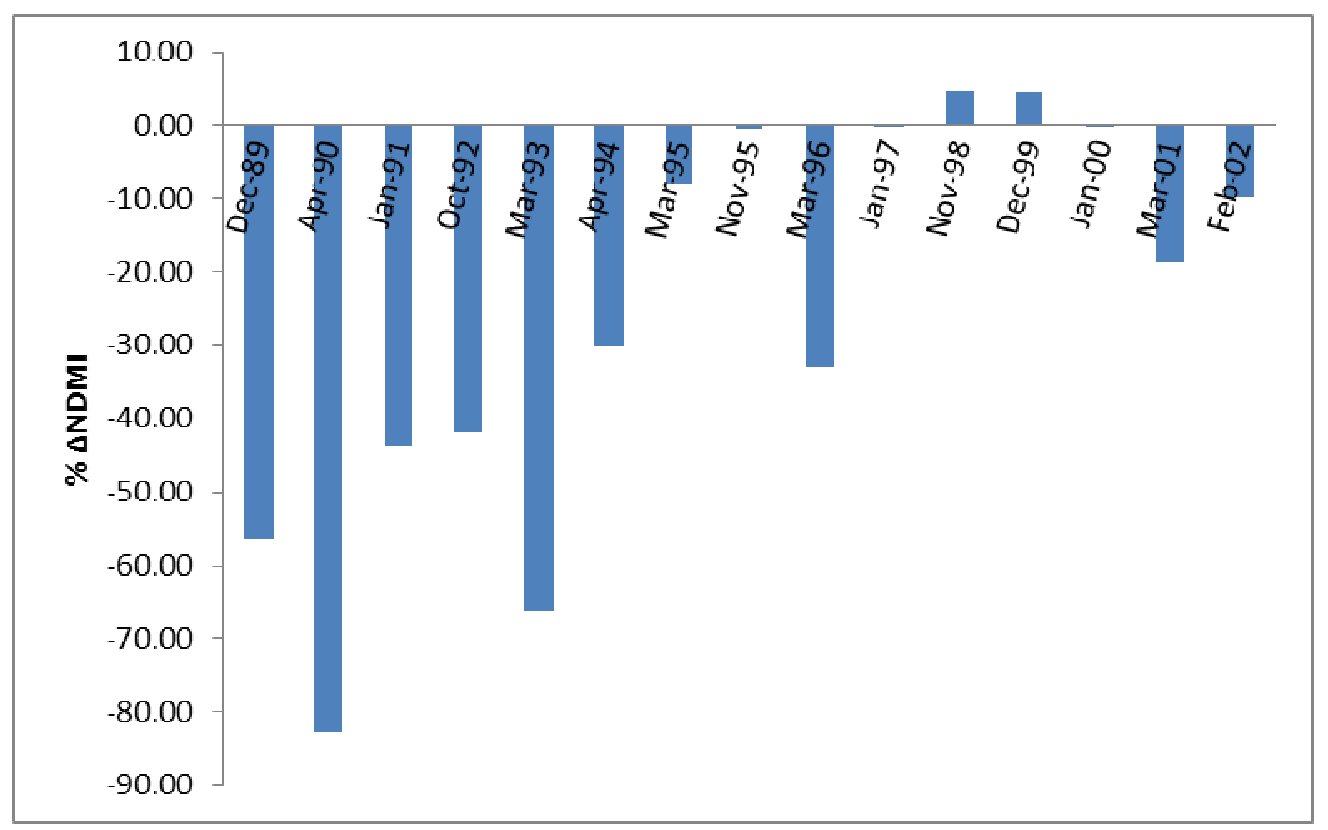

Figure 9. Vegetation recovery trend after chilling event 1989 "Christmas Freeze". The impacted area from Figure 6a was used to calculate rate of change in mean NDMI after event in impacted areas. The basal date $(t)$ is 1988 November. 


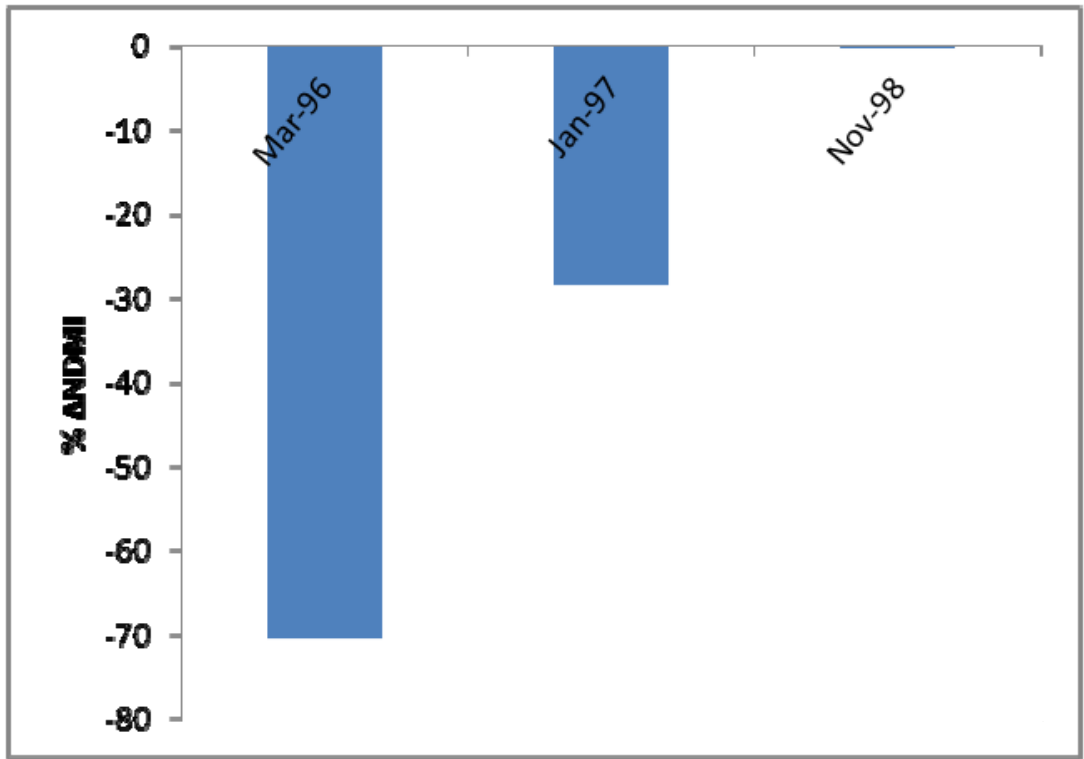

Figure 10. Vegetation recovery trend after 1996 chilling event. The impacted area from Figure $6 \mathrm{~b}$ was used to calculate rate of change in mean NDMI after event in impacted areas. The basal date (t) is 1995 November.

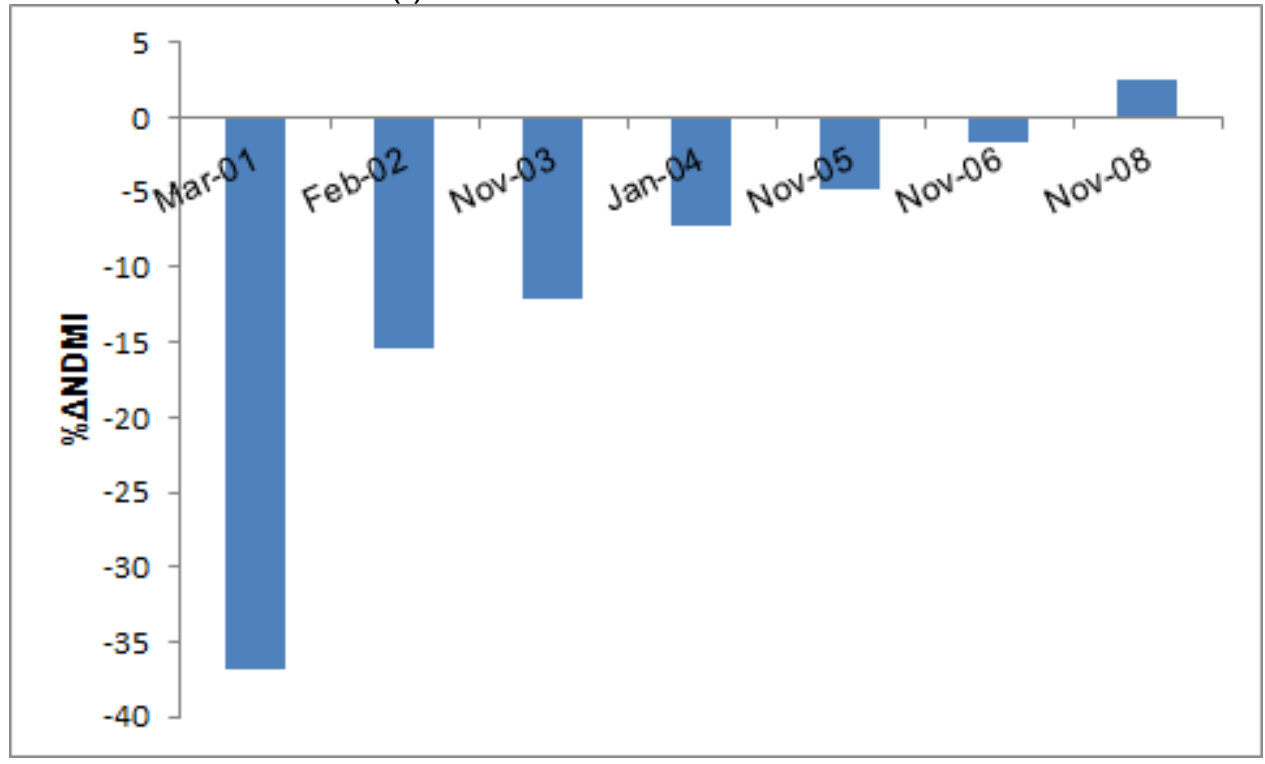

Figure 11. Vegetation recovery trend after 2001 chilling event. The impacted area from Figure $6 \mathrm{c}$ was used to calculate the rate of change in mean NDMI after event in impacted areas. The basal date $(\mathrm{t})$ is 2000 January. 


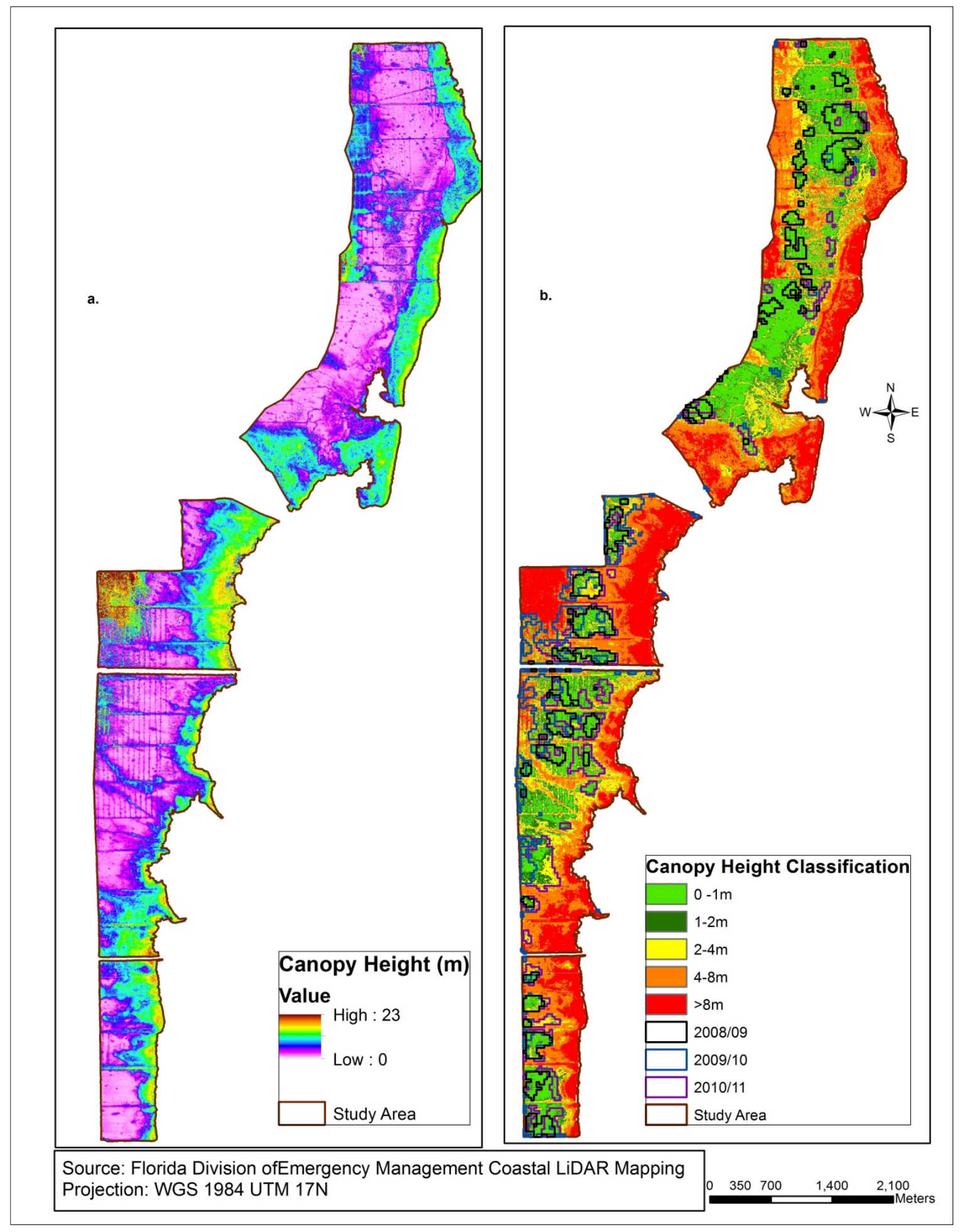

Figure 12. LiDAR canopy height (a) is classified into 5 intervals (b), with chilling events of February 2009, January 2010 and December 2010 overlaid. 


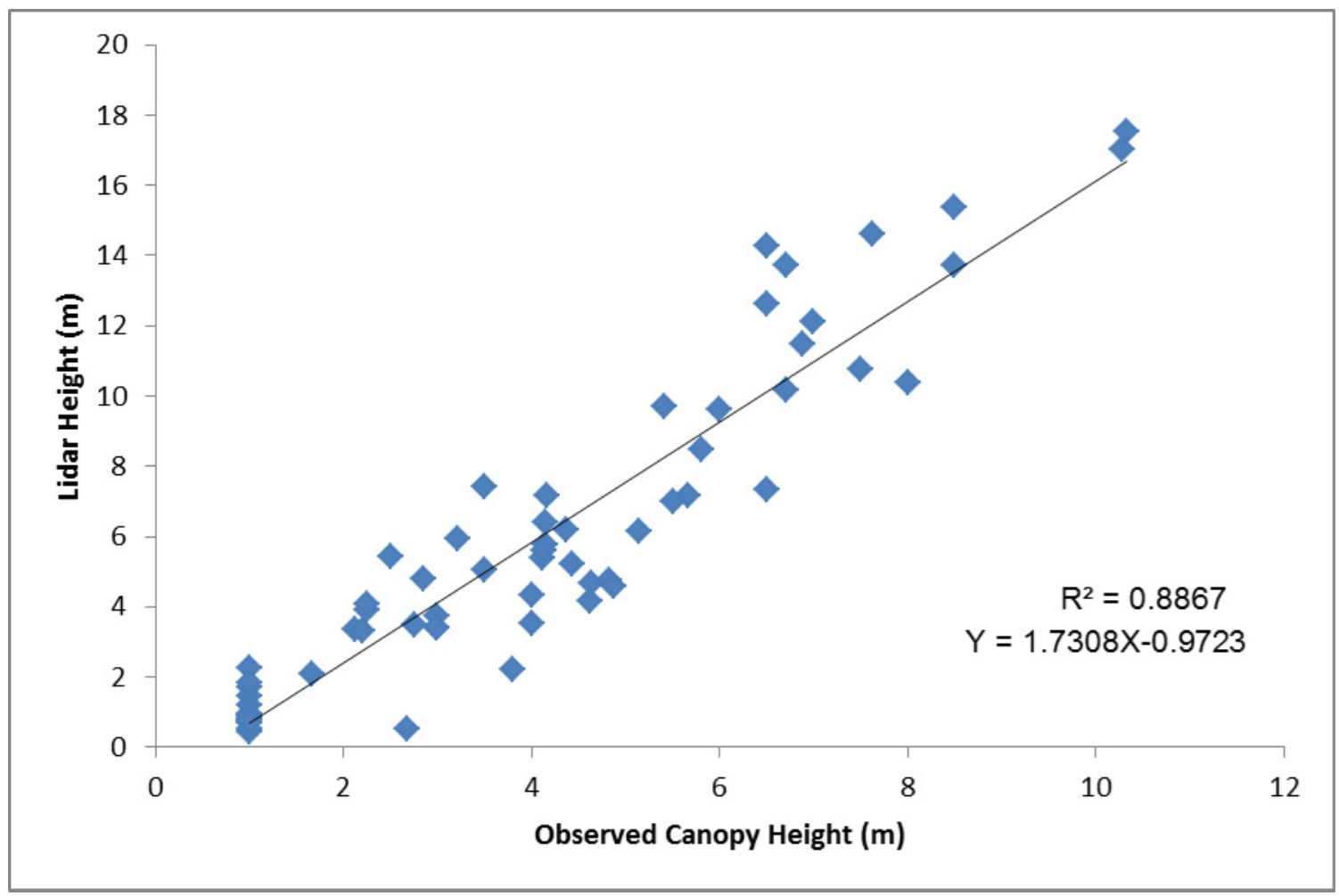

Figure 13. Regression Analysis of estimated LiDAR canopy height and field canopy height.

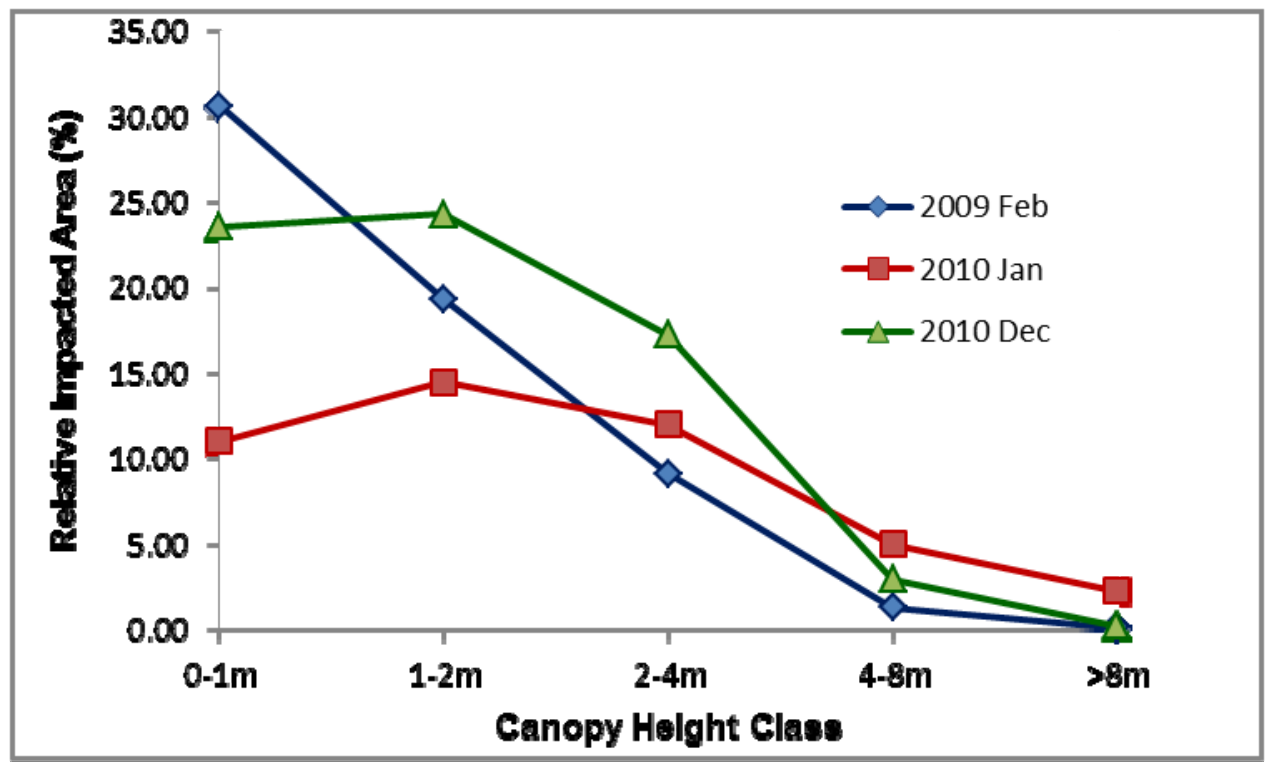

Figure 14. Distribution of chilling induced change areas in different canopy height classes. Relative impacted area is the area that has been impacted due to chilling event in each height class. Area of each height class was assumed 100 percent to calculate relative impacted area in percentage. 


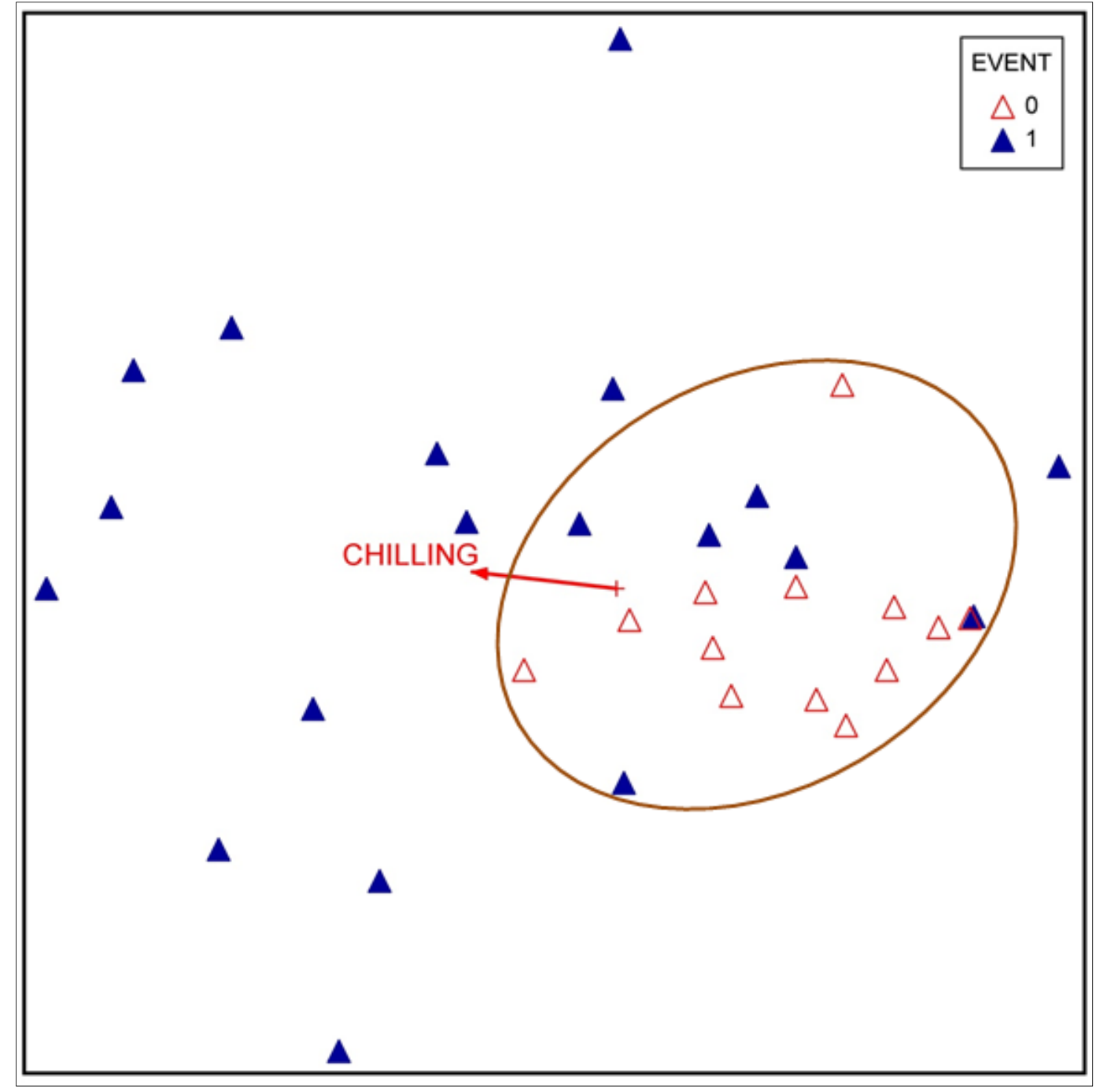

Figure 15. NMS ordination of chilling impacted sites (closed triangle and event 1 ) and unimpacted sites (open triangle and event 0 ) in dwarf mangrove community in study area. Impacted sites are the sites which were affected by chilling events either by 2001 or 2010. 

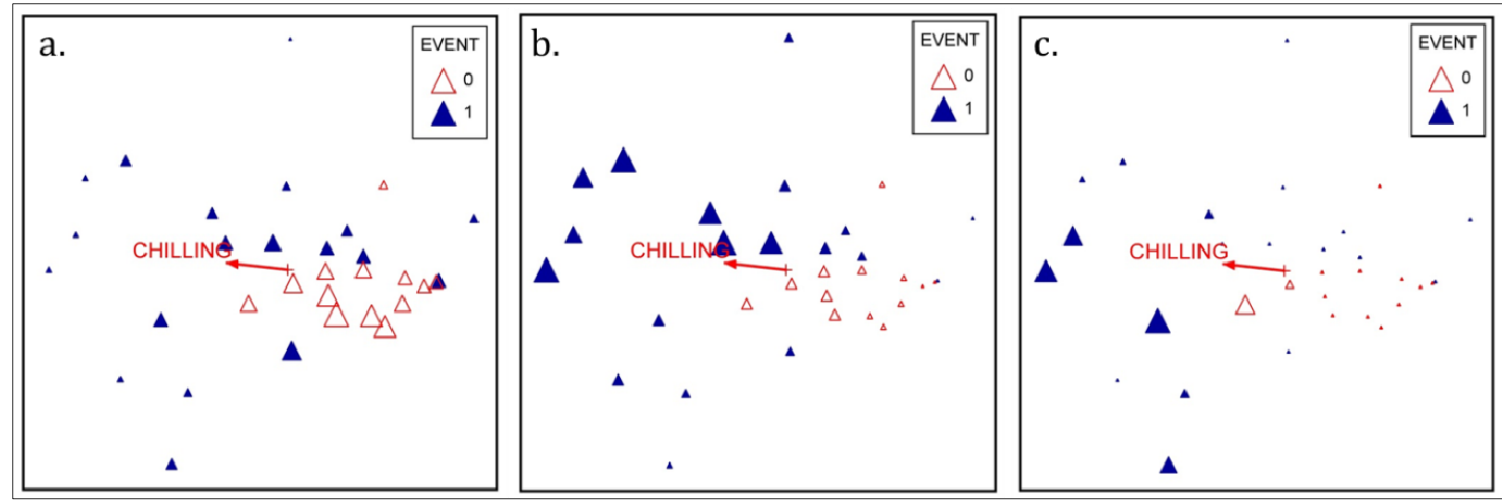

Figure 16. Relative cover of three major species in chilling impacted and unimpacted sites. a. Red Mangrove (Rhizophora mangle) b. White Mangrove (Laguncularia racemosa) c. Black Mangrove (Avicennia germinans). Open triangles in red color represent chilling unimpacted sites and closed triangles in blue color represents chilling impacted sites (or, Event 1 indicates chilling impacted sites and event 0 indicates unimpacted sites). The symbol size represents the relative abundance of species and scale is same for all species.

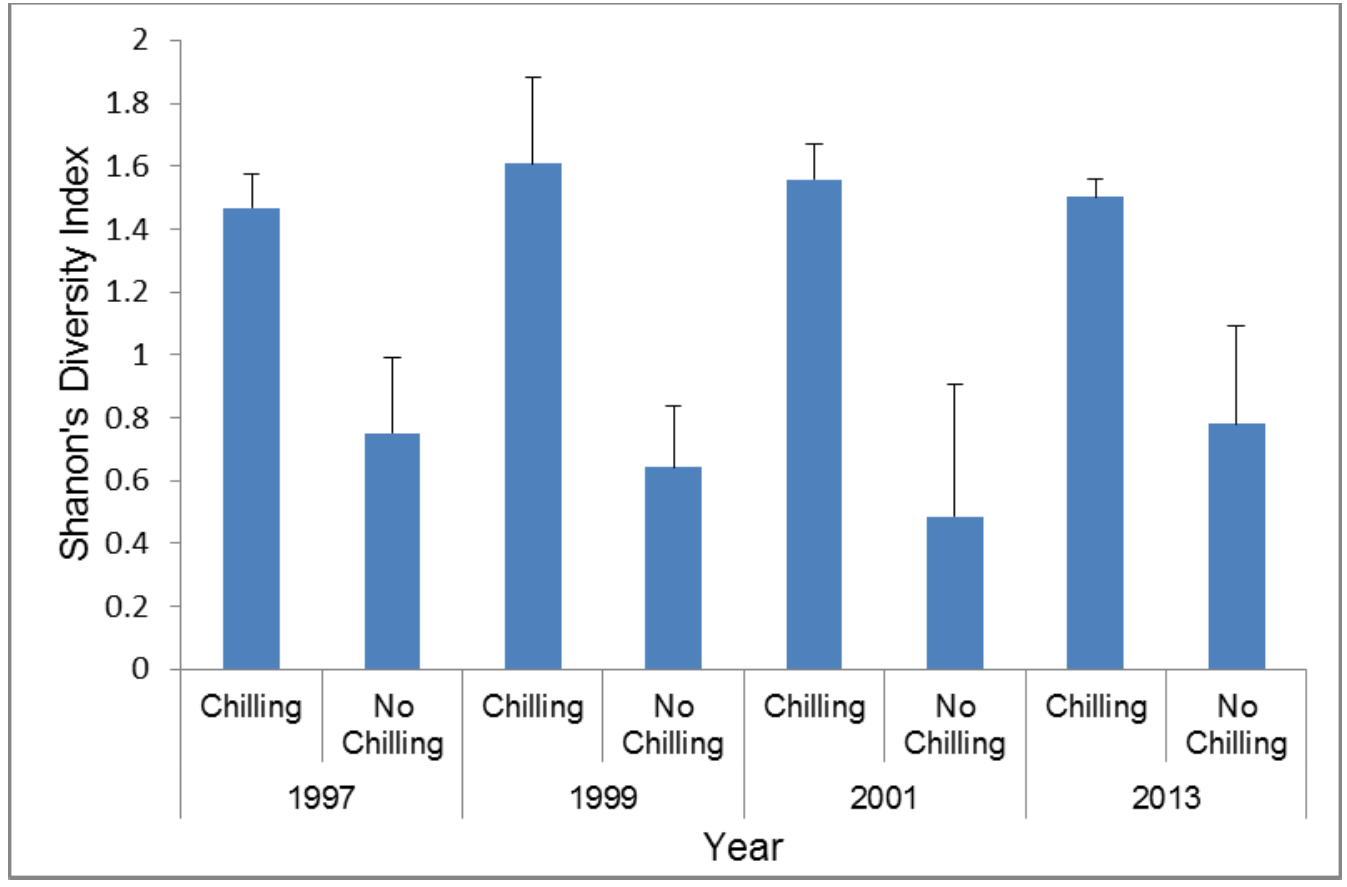

Figure 17. Mean Shannon's Diversity Index $\left(\mathrm{H}^{\prime}\right)$ for chilling impacted and unimpacted sites. 'Chilling' and 'No Chilling' respectively represent chilling impacted sites and unimpacted sites. Error bars represent standard deviations. 
Flowchart 1. Landsat image processing to develop chilling induced change map

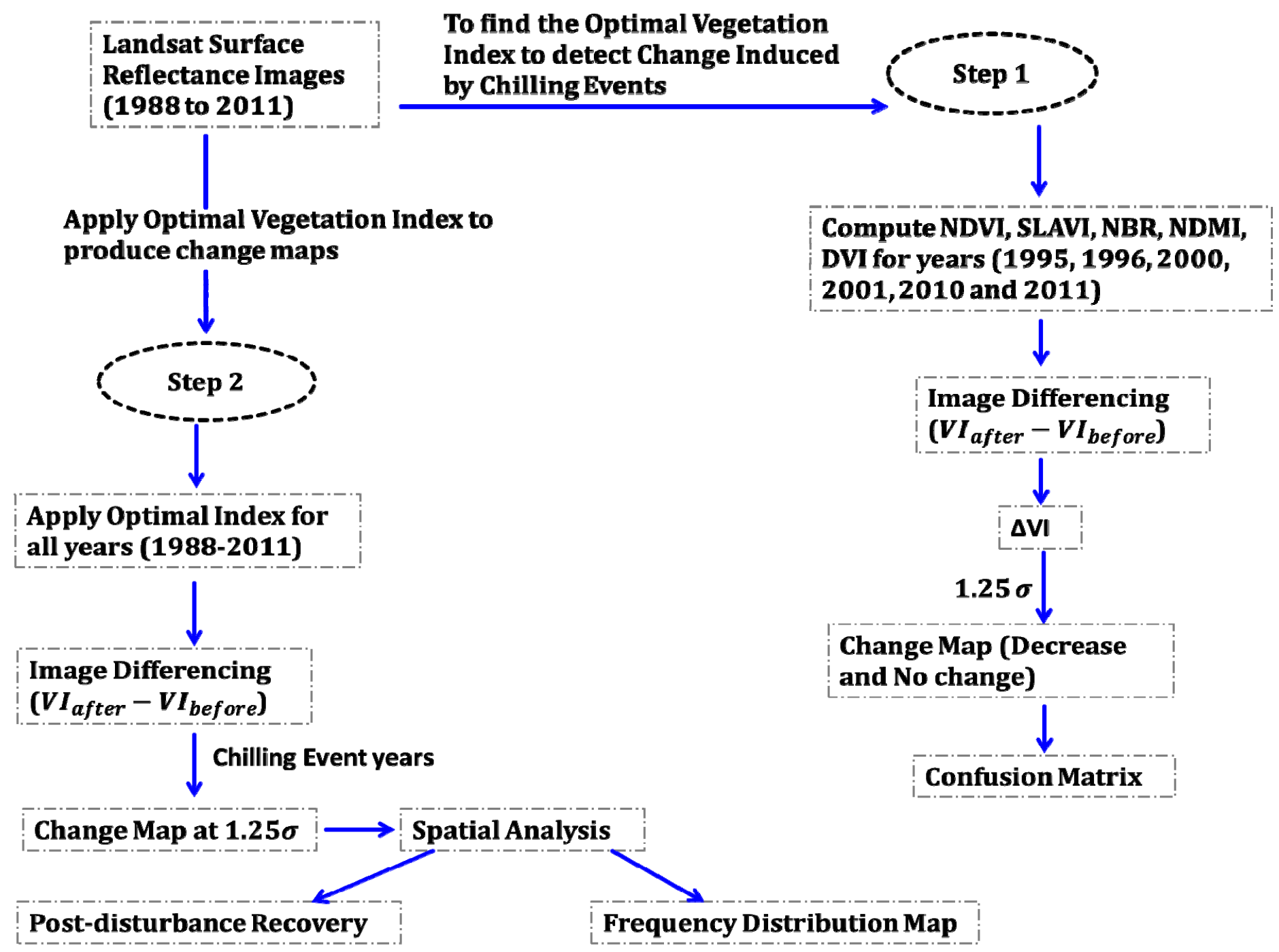


Flowchart 2. LiDAR data processing to estimate canopy height

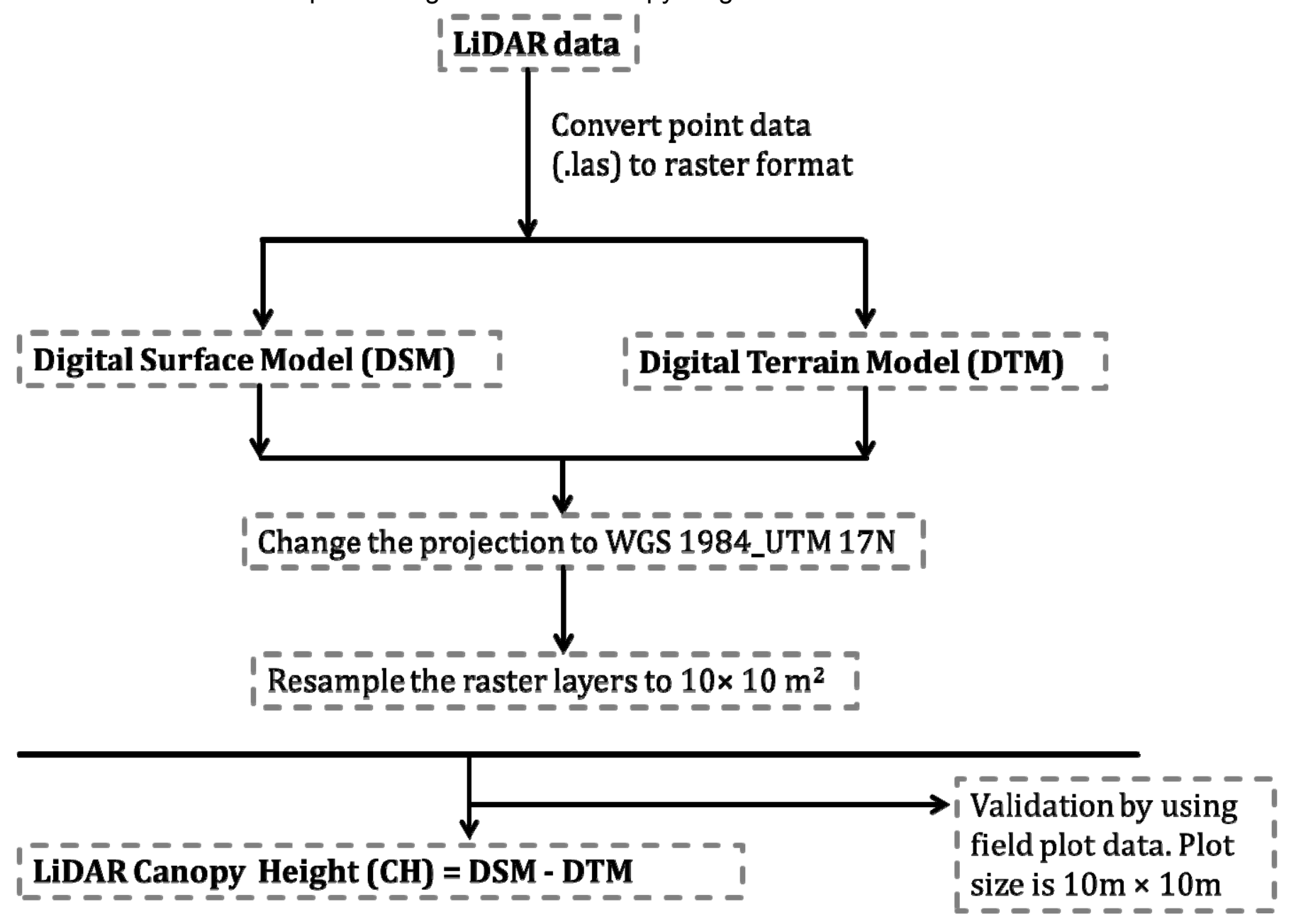


Table 1. Frequency of chilling events in Biscayne Bay, Florida and images bracketed to detect change induced by chilling event.

\begin{tabular}{|c|c|c|c|c|c|c|c|}
\hline $\begin{array}{l}\text { Chilling } \\
\text { Event }\end{array}$ & Date & $\begin{array}{l}\text { Total } \\
\text { Hours } \\
\end{array}$ & Lowest Temp ${ }^{\circ} \mathrm{C}$ & $\mathrm{CDH}$ & No. of Events & Before & After \\
\hline 1989 & $\begin{array}{r}2 / 25 / 1989 \\
12 / 24 / 1989 \\
12 / 25 / 1989\end{array}$ & $\begin{array}{c}2 \\
9 \\
11 \\
\end{array}$ & $\begin{array}{l}2.2 \\
0.6 \\
0.6\end{array}$ & 31 & 2 & 1988 Nov 18 & $1989 \mathrm{Dec} 31$ \\
\hline 1996 & $\begin{array}{r}1 / 9 / 1996 \\
2 / 5 / 1996 \\
2 / 17 / 1996 \\
\end{array}$ & $\begin{array}{c}\text { NA } \\
6 \\
2 \\
\end{array}$ & $\begin{array}{l}2.2 \\
2.2 \\
2.2 \\
\end{array}$ & 4.8 & 3 & 1995 Nov 14 & 1996 Mar 21 \\
\hline 2001 & $1 / 5 / 2001$ & 6 & 3 & 0 & 1 & 2000 Jan12 & 2001 Mar03 \\
\hline 2003 & $1 / 24 / 2003$ & 3 & 3 & 0 & 1 & 2002 Feb 18 & 2003 Jan20 \\
\hline 2008 & $1 / 3 / 2008$ & 5 & 1.7 & 3.7 & 1 & 2007Jan31 & 2008 Feb03 \\
\hline 2009 Feb & $2 / 5 / 2009$ & 1 & 2.7 & 0.3 & 1 & 2008 Nov17 & 2009 Feb05 \\
\hline 2010 Jan & $\begin{array}{l}1 / 10 / 2010 \\
1 / 11 / 2010 \\
\end{array}$ & $\begin{array}{l}8 \\
9\end{array}$ & $\begin{array}{r}1.2 \\
-0.6 \\
\end{array}$ & 29.3 & 1 & 2009 Oct 19 & 2010 Feb 08 \\
\hline $2010 \mathrm{Dec}$ & $\begin{array}{l}12 / 14 / 2010 \\
12 / 15 / 2010 \\
12 / 28 / 2010\end{array}$ & $\begin{array}{l}3 \\
7 \\
4\end{array}$ & $\begin{array}{l}1.7 \\
1.5 \\
1.2\end{array}$ & 10.6 & 2 & 2010 Oct 22 & 2011 Feb 27 \\
\hline
\end{tabular}

Note: $\mathrm{CDH}=$ Chilling Degree Hours 
Table 2. Classification accuracy comparisons of image differencing method of using different vegetation indices to detect change induced by chilling events.

\begin{tabular}{|cccc|}
\hline Index & Year & Overall Accuracy (\%) & K-coefficient \\
SLAVI & $1996 / 95$ & 72.32 & 0.48 \\
& $2001 / 00$ & 44.44 & 0.12 \\
& $2011 / 10$ & 70.32 & 0.38 \\
NDVI & $1996 / 95$ & 69.44 & 0.44 \\
& $2001 / 00$ & 55.55 & 0.30 \\
& $2011 / 10$ & 99 & 0.99 \\
NDMI & $1996 / 95$ & 86.11 & $\mathbf{0 . 7 3}$ \\
& $\mathbf{2 0 0 1 / 0 0}$ & 38.88 & $\mathbf{0 . 1 4}$ \\
& $\mathbf{2 0 1 1 / 1 0}$ & 99.67 & $\mathbf{0 . 9 9}$ \\
NBR & $1996 / 95$ & 86.11 & 0.72 \\
& $2001 / 00$ & 63.88 & 0 \\
& $2011 / 10$ & 99.67 & 0.99 \\
DVI & $1996 / 95$ & 36.11 & 0 \\
& $2001 / 00$ & 47.22 & 0.16 \\
& $2011 / 10$ & 97.74 & 0.95 \\
\hline
\end{tabular}

Table 3. Chilling events patch metrics

\begin{tabular}{|lllll|}
\hline Chilling Event & Frequency & Fractal Dimension & Mean Patch Size(ha) & SHDI \\
$1988 / 89$ & 45 & 1.05 & 3.47 & 0.36 \\
$1995 / 96$ & 57 & 1.03 & 1.87 & 0.28 \\
$2000 / 01$ & 52 & 1.04 & 2.97 & 0.23 \\
$2008 / 09$ & 57 & 1.04 & 2.49 & 0.34 \\
$2009 / 10$ & 58 & 1.04 & 1.89 & 0.28 \\
$2010 / 11$ & 52 & 1.04 & 2.97 & 0.36 \\
\hline
\end{tabular}

Note: Fractal dimension of a patch indicates the complexity of patch shape. Fractal dimension was calculated as $\log \left(\frac{l}{4}\right)=\log (s)$; where 'l' is the perimeter and 's' represent the area. The fractal dimension has 0-2 value, 1 indicates the perfect square shape and 2 indicates the complex perimeter. SHDI is the Shannon's Diversity Index which measure patch richness in a landscape. $S H D I=\sum_{i=1}^{m} p_{i} l n p_{i}$; where, pi is the proportion of the landscape occupied by patch type (class) $i$. $S H D I=0$ means only 1 patch and $S H D I>0$ indicates the high diversity of patches.

Table 4. MRPP analysis of chilling impacted site and unimpacted site

\begin{tabular}{|lllll|}
\hline Year & 1997 & 1999 & 2001 & 2013 \\
Agreement Statistics (A) & 0.27 & 0.34 & 0.36 & 0.43 \\
P-Value & $<0.01$ & $<0.01$ & $<0.01$ & $<0.01$ \\
\hline
\end{tabular}


Table 5. Indicator species across chilling impacted sites and unimpacted sites at different years. 'Chilling' and 'No Chilling' respectively represent chilling impacted sites and unimpacted sites.

\begin{tabular}{|c|c|c|c|c|}
\hline Year & Treatment & Indicator Species & Indicator Value (\%) & $p$-value \\
\hline \multirow{3}{*}{1997} & No Chilling & Rhizophora mangle & 80 & 0.02 \\
\hline & \multirow{2}{*}{ Chilling } & Laguncularia racemosa & 77 & 0.08 \\
\hline & & Philoxerus vermicularis & 100 & 0.02 \\
\hline \multirow{5}{*}{1999} & \multirow{5}{*}{ Chilling } & Avicennia germinans & 92 & 0.05 \\
\hline & & Laguncularia racemosa & 77 & 0.10 \\
\hline & & Philoxerus vermicularis & 100 & 0.01 \\
\hline & & Rhabdadenia biflora & 67 & 0.10 \\
\hline & & $\begin{array}{l}\text { Sesuvium } \\
\text { portulacastrum }\end{array}$ & 67 & 0.10 \\
\hline \multirow{5}{*}{2001} & \multirow{5}{*}{ Chilling } & Avicennia germinans & 100 & 0.10 \\
\hline & & Laguncularia racemosa & 96 & 0.10 \\
\hline & & Conocarpus erectus & 99 & 0.10 \\
\hline & & Philoxerus vermicularis & 100 & 0.10 \\
\hline & & Rhabdadenia biflora & 100 & 0.10 \\
\hline \multirow{4}{*}{2013} & No Chilling & Rhizophora mangle & 80 & 0.01 \\
\hline & \multirow{3}{*}{ Chilling } & Avicennia germinans & 100 & 0.01 \\
\hline & & Conocarpus erectus & 100 & 0.01 \\
\hline & & Philoxerus vermicularis & 87 & 0.03 \\
\hline
\end{tabular}

Notes: Indicator values (IVs) were calculated on the basis of relative abundance and relative frequency in PC-ORD6. $p$-Value was computed by using Monte Carlo test of significance of each IV by using 10,000 permutations . 


\section{References}

Andersen, H.E., Reutebuch, S.E., McGaughey, R.J., 2006. A rigorous assessment of tree height measurements obtained using airborne lidar and conventional field methods. Canadian Journal of Remote Sensing 32, 355-366.

Behrenfeld, M.J., Randerson, J.T., McClain, C.R., Feldman, G.C., Los, S.O., Tucker, C.J., Falkowski, P.G., Field, C.B., Frouin, R., Esaias, W.E., Kolber, D.D., Pollack, N.H., 2001. Biospheric primary production during an ENSO transition. Science 291, 2594-2597.

Brandtberg, T., Warner, T.A., Landenberger, R.E., McGraw, J.B., 2003. Detection and analysis of individual leaf-off tree crowns in small footprint, high sampling density lidar data from the eastern deciduous forest in North America. Remote Sensing of Environment 85, 290-303.

Burrough, P. A., 1986, Principles of Geographical Information Systems for Land Resources Assessment. Monographs on Soil and Resources Survey, 12.

Cakir, H.I., Khorram, S., Nelson, S.A.C., 2006. Correspondence analysis for detecting land cover change. Remote Sensing of Environment 102, 306-317.

Cavanaugh, K.C., Kellner, J.R., Forde, A.J., Gruner, D.S., Parker, J.D., Rodriguez, W., Feller, I.C., 2013. Poleward expansion of mangroves is a threshold response to decreased frequency of extreme cold events. PNAS 201315800.

Chapman, V.J., 1976. Mangrove vegetation. J. Cramer, Vaduz (Germany). $447 \mathrm{pp}$.

Connell, J.H. 1978. Diversity in tropical rain forests and coral reefs. Science 199, 1302-1310.

Coppin, P., Jonckheere, I., Nackaerts, K., Muys, B., Lambin, E., 2004. Review article digital change detection methods in ecosystem monitoring: a review. International Journal of Remote Sensing 25, 1565-1596.

Díaz, B.M., Blackburn, G.A., 2003. Remote sensing of mangrove biophysical properties: Evidence from a laboratory simulation of the possible effects of background variation on spectral vegetation indices. International Journal of Remote Sensing 24, 53-73.

Dufrêne, M., Legendre, P., 1997. Species assemblages and indicator species. The need for a flexible asymmetrical approach. Ecological Monographs 67, 345366. 
Duke, N., Ball, M., Ellison, J., 1998. Factors influencing biodiversity and distributional gradients in mangroves. Global Ecology \& Biogeography Letters 7, 27-47.

Ellis, W.L., Bowles, J.W., Erickson, A.A., Stafford, N., Bell, S.S., Thomas, M., 2006. Alteration of the chemical composition of mangrove (Laguncularia racemosa) leaf litter fall by freeze damage. Estuarine, Coastal and Shelf Science 68, 363-371.

Escuin, S., Navarro, R., Fernández, P., 2008. Fire severity assessment by using NBR (Normalized Burn Ratio) and NDVI (Normalized Difference Vegetation Index) derived from LANDSAT TM/ETM images. International Journal of Remote Sensing 29, 1053-1073.

Ewers, R.M., Banks-Leite, C., 2013. Fragmentation impairs the Microclimate Buffering Effect of Tropical Forests. PLoS ONE 8, e58093.

Faith, D.P., Minchin, P.R., Belbin, L., 1987. Compositional dissimilarity as a robust measure of ecological distance. Vegetation 69, 57-68.

Gao, J., 1999. A comparative study on spatial and spectral resolutions of satellite data in mapping mangrove forests. International Journal of Remote Sensing 20, 2823-2833.

Hall, R. J., Skakun, R. S., Arsenault, E. J., \& Case, B. S., 2006. Modeling forest stand structure attributes using Landsat ETM+ data: Application to mapping of aboveground biomass and stand volume. Forest Ecology and Management, 225(1), 378-390.

Healey, S.P., Yang, Z., Cohen, W.B., Pierce, D.J., 2006. Application of two regression-based methods to estimate the effects of partial harvest on forest structure using Landsat data. Remote Sensing of Environment 101, 115-126.

IPCC, Climate Change 2007. The physical science basis, Intergovernmental Panel on Climate Change, Geneva, 2007, 18p.

Kennedy, R.E., Cohen, W.B., Schroeder, T.A., 2007. Trajectory-based change detection for automated characterization of forest disturbance dynamics. Remote Sensing of Environment 110, 370-386.

Krauss, K.W., Lovelock, C.E., McKee, K.L., López-Hoffman, L., Ewe, S.M.L., Sousa, W.P., 2008. Environmental drivers in mangrove establishment and early development: A review. Aquatic Botany 89, 105-127.

Kruskal, J.B., 1964. Multidimensional scaling by optimizing goodness of fit to a nonmetric hypothesis. Psychometrika 29, 1-27. 
Lefsky, M.A., Cohen, W.B., Parker, G.G., Harding, D.J., 2002. Lidar Remote Sensing for Ecosystem Studies Lidar, an emerging remote sensing technology that directly measures the three-dimensional distribution of plant canopies, can accurately estimate vegetation structural attributes and should be of particular interest to forest, landscape, and global ecologists. BioScience 52, 19-30.

Legendre, P., Gallagher, E.D., 2001. Ecologically meaningful transformations for ordination of species data. Oecologia 129, 271-280.

Leslie, A., Mencuccini, M., Perks, M., 2014. Frost damage to eucalypts in a shortrotation forestry trial in Cumbria (England). iForest - Biogeosciences and Forestry 7, 155-160.

Lim, K., Treitz, P., Wulder, M., St-Onge, B., Flood, M., 2003. LiDAR remote sensing of forest structure. Progress in Physical Geography 27, 88-106.

Lindberg, E., Hollaus, M., 2012. Comparison of methods for estimation of stem volume, stem number and basal area from Airborne Laser Scanning Data in a Hemi-Boreal Forest. Remote Sensing 4, 1004-1023.

Liu, J. (1993), Creating a method for optimal threshold determination for change detection in an urban environment, M.S. thesis, Department of Geography, University of Utah.

Lugo, A.E., Patterson-Zucca, C. P., 1977. The impact of low temperature stress on mangrove structure and growth. Tropical Ecology. Vol. 18: 149-161.

Lupo, F., Reginster, I., Lambin, E.F., 2001. Monitoring land-cover changes in West Africa with SPOT Vegetation: Impact of natural disasters in 1998-1999. International Journal of Remote Sensing 22, 2633-2639.

Luther, J.E., Franklin, S.E., Hudak, J., Meades, J.P., 1997. Forecasting the susceptibility and vulnerability of balsam fir stands to insect defoliation with Landsat Thematic Mapper data. Remote Sensing of Environment 59, 77-91.

Macleod, R.D., Congalton, R.G.,1998. A quantitative comparison of change detection algorithms for monitoring Eelgrass from remotely sensed data. Photogrammetric Engineering and Remote Sensing, Vol 64(3), 207-216.

Markley, J.L., McMillan, C., Thompson Jr., G.A., 1982. Latitudinal differentiation in response to chilling temperatures among populations of three mangroves, Avicennia germinans, Laguncularia racemosa, and Rhizophora mangle, from the western tropical Atlantic and Pacific Panama. Can. J. Bot. 60, 2704-2715.

Mas, J.-F., 1999. Monitoring land-cover changes: A comparison of change detection techniques. International Journal of Remote Sensing 20, 139-152. 
Masek, J.G., Huang, C., Wolfe, R., Cohen, W., Hall, F., Kutler, J., Nelson, P., 2008. North American forest disturbance mapped from a decadal Landsat record. Remote Sensing of Environment 112, 2914-2926.

Masek, J.G., Vermote, E.F., Saleous, N.E., Wolfe, R., Hall, F.G., Huemmrich, K.F., Gao, F., Kutler, J., Lim, T.-K., 2006. A Landsat surface reflectance dataset for North America, 1990-2000. IEEE Geoscience and Remote Sensing Letters 3, 68-72.

McCune, B. and M. J. Mefford. 2011. PC-ORD. Multivariate analysis of ecological data. Version 6. MjM Software, Gleneden Beach, Oregon, U.S.A.

McCune, B., Grace, J.B., 2002. Analysis of ecological communities. MjM Software, Gleneden Beach, OR, USA

McMillan C, Sherrod CL. 1986. The chilling tolerance of black mangrove, Avicennia germinans, from the Gulf of Mexico coast of Texas, Louisiana and Florida. Contributions in Marine Science 29, 9-16.

Mielke Jr., P.W., 1984. Meteorological applications of permutation techniques based on distance functions, in: P.R. Krishnaiah and P.K. Sen (eds.), Handbook of Statistics. Elsevier, pp. 813-830.

Miller, J.D., Yool, S.R., 2002. Mapping forest post-fire canopy consumption in several overstory types using multi-temporal Landsat TM and ETM data. Remote Sensing of Environment 82, 481-496.

Minchin, P.R., 1987. An evaluation of the relative robustness of techniques for ecological ordination. Vegetatio 69, 89-107.

Muchoney, D.M., Haack, B.N., 1994. Change detection for monitoring forest defoliation. Photogrammetric engineering and remote sensing 60, 1243-1251.

Myers, R.L.,1986. Florida's freezes: An analog of short duration nuclear winter events in the tropics. Atmospheric and Biological Sciences 49(2), 104-115.

Nelson, R.F., 1983. Detecting forest canopy change due to insect activity using landsat MSS: a vegetative index difference (VID) transformation most accurately delineates forest canopy change. Photogrammetric engineering and remote sensing 49, 1303-1314.

Olmsted, I., Dunevitz, H., Platt, W.J., 1993. Effects of freezes on tropical trees in Everglades National Park, Florida, USA. Tropical Ecology. Vol. 34(1), 17-34.

Osland, M.J., Enwright, N., Day, R.H., Doyle, T.W., 2013. Winter climate change and coastal wetland foundation species: salt marshes vs. mangrove forests in the southeastern United States. Global Change Biology 19, 1482-1494. 
Rehage,J., Gaiser, E., Heithaus, M., Ross, M., Ruiz, P., 2010. Effects of a rare cold snap on Everglades biota: what are the long-term consequences for the ecosystem? Network News Spring.Vol. 23(1). http://news. Iternet.edu/Article348.html

Ridd, M.K., Liu, J., 1998. A Comparison of four algorithms for change detection in an urban environment. Remote Sensing of Environment 63, 95-100.

Ross, M. S., Carrlngton, M., Flynn, L. J. and Ruiz, P. L., 2001. Forest Succession in Tropical Hardwood Hammocks of the Florida Keys: Effects of Direct Mortality from Hurricane Andrew. Biotropica 33, 23-33

Ross, M.S., Ruiz, P.L., Sah, J.P., Hanan, E.J., 2009. Chilling damage in a changing climate in coastal landscapes of the subtropical zone: a case study from south Florida. Global Change Biology 15, 1817-1832.

Ruiz, P. L., Ross, M.S., Walters, J., Hwang, B., Evelyn, G., Franco, T., 2002. L31E Wetland and Flow Monitoring (SFWMD Conract C-12409). Vegetation of coastal wetlands in Biscayne National Park: Blocks 6-8. Submitted to Southeast Environmental Research Center Florida International University.

Schroeder, T.A., Wulder, M.A., Healey, S.P., Moisen, G.G., 2011. Mapping wildfire and clearcut harvest disturbances in boreal forests with Landsat time series data. Remote Sensing of Environment 115, 1421-1433.

Sexton, J.O., Bax, T., Siqueira, P., Swenson, J.J., Hensley, S., 2009. A comparison of lidar, radar, and field measurements of canopy height in pine and hardwood forests of southeastern North America. Forest Ecology and Management 257, 1136-1147.

Shannon, C.E., Weaver, W., 1949. The mathematical theory of communication. University of Illinois Press, Urbana, IL, USA.

Sherrod, C. L., Hockaday, D.L., McMillan, C., 1986. Survival of red mangrove, Rhizophora mangle, on the Gulf of Mexico coast of Texas. Contributions in Marine Science, 29, 27-36.

Singh, A., 1989. Review Article Digital change detection techniques using remotely-sensed data. International Journal of Remote Sensing 10, 989-1003.

Spruce, J.P., Sader, S., Ryan, R.E., Smoot, J., Kuper, P., Ross, K., Prados, D., Russell, J., Gasser, G., McKellip, R., Hargrove, W., 2011. Assessment of MODIS NDVI time series data products for detecting forest defoliation by gypsy moth outbreaks. Remote Sensing of Environment 115, 427-437.

Spruce, J.P., Sader, S., Ryan, R.E., Smoot, J., Kuper, P., Ross, K., Prados, D., Russell, J., Gasser, G., McKellip, R., Hargrove, W., 2011. Assessment of MODIS 
NDVI time series data products for detecting forest defoliation by gypsy moth outbreaks. Remote Sensing of Environment 115, 427-437.

Stevens, P.W., Fox, S.L., Montague, C.L., 2006. The interplay between mangroves and saltmarshes at the transition between temperate and subtropical climate in Florida. Wetlands Ecol Manage 14, 435-444.

Stuart, S.A., Choat, B., Martin, K.C., Holbrook, N.M., Ball, M.C., 2007. The role of freezing in setting the latitudinal limits of mangrove forests. New Phytologist 173, 576-583.

Townsend, P.A., Singh, A., Foster, J.R., Rehberg, N.J., Kingdon, C.C., Eshleman, K.N., Seagle, S.W., 2012. A general Landsat model to predict canopy defoliation in broadleaf deciduous forests. Remote Sensing of Environment 119, 255-265.

Tucker, C.J., 1979. Red and photographic infrared linear combinations for monitoring vegetation. Remote Sensing of Environment 8, 127-150.

Turner, M.G., 1990. Spatial and temporal analysis of landscape patterns. Landscape Ecol 4, 21-30.

Vermote, E.F., El Saleous, N., Justice, C.O., Kaufman, Y.J., Privette, J.L., Remer, L., Roger, J.C., Tanré, D., 1997. Atmospheric correction of visible to middle-infrared EOS-MODIS data over land surfaces: Background, operational algorithm and validation. Journal of Geophysical Research: Atmospheres 102, 17131-17141.

Wasser, L., Day, R., Chasmer, L., Taylor, A., 2013. Influence of vegetation structure on Lidar-derived canopy height and fractional cover in forested riparian buffers during leaf-off and leaf-on conditions. PLoS ONE 8, e54776.

Wilson, E.H., Sader, S.A., 2002. Detection of forest harvest type using multiple dates of Landsat TM imagery. Remote Sensing of Environment 80, 385-396.

Yanez-Espinosa, L., Flores, J., 2011. A review of sea-level rise effect on mangrove forest species: Anatomical and morphological modifications in: Casalegno, S. (Ed.), Global Warming Impacts - Case Studies on the Economy, Human Health, and on Urban and Natural Environments. InTech.

Zhu, Z., Woodcock, C.E., Olofsson, P., 2012. Continuous monitoring of forest disturbance using all available Landsat imagery. Remote Sensing of Environment 122, 75-91. 